\title{
MicroRNA-22 mediates the cisplatin resistance of osteosarcoma cells by inhibiting autophagy via the PI3K/Akt/mTOR pathway
}

\author{
CHEN-YANG MENG $^{1 *}$, ZHEN-QUN ZHAO $^{1 *}$, RUI BAI $^{1}$, WEI ZHAO ${ }^{1}$, YU-XING WANG $^{1}$, \\ HUI-QIN XUE ${ }^{2}$, LIANG SUN ${ }^{1}$, CHAO SUN $^{1}$, WEI FENG ${ }^{1}$ and SHI-BING GUO ${ }^{1}$
}

Departments of ${ }^{1}$ Orthopedic Surgery and ${ }^{2}$ Rehabilitation, Second Affiliated Hospital of Inner Mongolia Medical University, Huimin, Hohhot, Inner Mongolia 010030, P.R. China

Received September 11, 2019; Accepted January 27, 2020

DOI: $10.3892 /$ or.2020.7492

\begin{abstract}
Osteosarcoma (OS) is the most common primary malignant tumor of the bone affecting children and adolescents. Chemotherapy is now considered as a standard component of OS treatment, not only for children, but also for adults. However, chemoresistance continues to pose a challenge to therapy. Inhibition of autophagy has been demonstrated to decrease chemoresistance in OS. Moreover, microRNA-22 (miR-22) inhibits autophagy, leading to an improvement in the sensitivity of cisplatin (CDDP) in OS. The aim of the present study was therefore to investigate whether miR-22 could mediate the CDDP resistance of OS cells by inhibiting autophagy via the phosphoinositide 3-kinase (PI3K)/Akt/mammalian target of rapamycin (mTOR) pathway. Cell proliferation assay, LC3 flow cytometry assay and monodansylcadaverine staining in MG63 cells and CDDP resistance cells (MG63/CDDP) were performed to explore to role of miR-22 and CDDP in OS chemoresistance. Inoculation of tumor cells in an in vivo model, reverse transcription-quantitative PCR (RT-qPCR) assay, western blot analysis, and immunohistochemistry analysis were performed to investigate
\end{abstract}

Correspondence to: Professor Shi-Bing Guo or Professor Wei Feng, Department of Orthopedic Surgery, Second Affiliated Hospital of Inner Mongolia Medical University, 1st Yinfang Avenue, Huimin, Hohhot, Inner Mongolia 010030, P.R. China

E-mail: guoshibing2017@sina.com

E-mail: 603261696@qq.com

*Contributed equally

Abbreviations: OS, osteosarcoma; miRNA, microRNA; miR-22, microRNA-22; CDDP, cisplatin; LC3, microtubule-associated protein 1 light chain 3; MTDH, metadherin; PTEN, phosphatase and tensin homolog deleted on chromosome 10; PI3K, phosphoinositide 3-kinase; mTOR, mammalian target of rapamycin; MDC, monodansylcadaverine; ANOVA, analysis of variance; IOD, integral optical density

Key words: microRNA-22, cisplatin, chemoresistance, osteosarcoma, autophagy the role of miR-22 and CDDP in the PI3K/Akt/mTOR pathway as it is affected by autophagy. The results revealed that miR-22 inhibited the proliferation of MG63 and MG63/CDDP cells, and enhanced the anti-proliferative ability of CDDP in vivo and in vitro. miR-22 mediated the CDDP resistance of OS cells by inhibiting autophagy and decreasing CDDP-induced autophagy via downregulation of the expression of PI3K, Akt, and mTOR at the mRNA level, and the expression of PI3K, phosphorylated (p)-Akt, and p-mTOR at the protein level. It was also convincingly demonstrated that miR-22 mediates the CDDP resistance of OS by inhibiting autophagy via the PI3K/Akt/mTOR pathway. Furthermore, in the MG63 cells that were affected by CDDP, the role of miR-22 was shown to be similar to that of the investigated inhibitor of PI3K (wortmannin) in terms of regulating the PI3K/Akt/mTOR pathway, and wortmannin could also promote the effect of miR-22. Interestingly, CDDP was demonstrated to induce autophagy by inhibiting the PI3K/Akt/mTOR pathway, whereas the pathway was upregulated in the state of chemoresistance. In conclusion, downregulation of the PI3K/Akt/mTOR pathway was shown to assist in the process of preventing chemoresistance.

\section{Introduction}

Osteosarcomas (OS) are uncommon tumors. Despite their rarity, however, OS is the most common primary malignancy tumor of the bone affecting children and adolescents (1). OS comprises $56 \%$ of all bone cancers in individuals under 20 years of age (2). In children, the peak incidence occurs between 13 and 16 years of age (3), and the most common site of OS is the metaphysis of long bones, especially the distal femur (2). Chemotherapy is now considered as a standard component of OS treatment, not only in children, but also in adults. The long-term survival rate following the incidence of a local tumor without chemotherapy has been reported as being only $16 \%$, whereas treatment with $\geq 3$ types of chemotherapy has been shown to improve the survival rate to $70 \%$ (4). Clinically, the traditional first-line chemotherapy regimen for OS is a combination of doxorubicin (DOX), cisplatin (CDDP), and methotrexate (MTX) (5). However, the development of drug resistance leads to a decrease in the therapeutic efficacy of the drugs, and an increasing number of studies are focusing on this issue. 
MicroRNAs (miRNAs) have been studied and reported on in numerous fields. miRNAs bind to the 3 -untranslated region (3'-UTR), either perfectly or imperfectly, to contribute to the translational suppression, or the degradation, of different target mRNAs (6). In addition, they have been demonstrated to be endogenous small RNA molecules that are able to regulate diverse biological functions, including tumorigenesis, progression and chemosensitivity of different cancer types $(7,8)$. Previously published studies have revealed that miRNAs have a crucial role in the drug responsiveness of OS $(9,10)$. That the regulation of autophagy is associated with OS has been confirmed $(11,12)$. In addition, activating autophagy has been shown to cause cytotoxic drugs to develop drug resistance $(13,14)$. It is now generally well understood that miRNAs exert a role in autophagy to regulate drug resistance in OS treatment. It was reported that miR-101 suppressed the expression of autophagy-related genes including LC3 and Atg5 in U2OS cells, and promoted cell sensitivity to DOX (15). Furthermore, miR-410 was shown to markedly inhibit autophagy by regulating autophagy-related gene 16L1 expression, thereby enhancing chemosensitivity (16).

The main focus of the present study was on microRNA-22 (miR-22), which is located on chromosome 17p13 and fulfills crucial roles as a tumor suppressor in certain types of malignancies $(17,18)$. It has been reported that overexpression of miR-22 significantly decreased cell proliferation and survival, and induced cell apoptosis in p53-mutated colon cancer cells (19). In addition, miR-22 was shown to target the truncated neurokinin-1 receptor and estrogen receptor- $\alpha$ to suppress the proliferation, invasion and metastasis of breast cancer cells (20). miR-22 was subsequently shown to enhance the radiosensitivity of small cell lung cancer cells through targeting the ATPase, WRN helicase interacting protein 1 (WRNIP1) (21). With regard to studies of OS, the level of miR-22 was found to be significantly decreased in patients with OS, and miR-22 could target S100A11 to increase the sensitivity of CDDP by preventing MG63 cells from proliferating and metastasizing (22). miR-22 was also shown to suppress high-mobility-group box 1 (HMGB1)-regulated autophagy in OS cells treated with DOX and CDDP $(23,24)$. These studies have suggested that miR-22 is associated with autophagy, and moreover, that it is able to regulate autophagy by targeting certain autophagy-related genes, such that miR-22 can affect the drug sensitivity of OS treatments. In our previous study, we mainly argued that CDDP could increase the autophagy of MG63 cells and the expression of autophagy-related genes including microtubule-associated protein 1 light chain 3 (LC3), autophagy related 5 (ATG5) and Beclin-1 (BECNI) and miR-22 could inhibit the upregulation of those genes induced by CDDP. However, the specific pathway associated with miR-22 and the effect of miR-22 on MG63 and CDDP-resistant cells still need to be investigated (25). In addition, only a few studies have focused attention on the pathway that is influenced by miR-22 in OS. It has been reported that miR-22-3p enhanced the chemosensitivity of gastrointestinal stromal tumor cell lines to CDDP via the phosphatase and tensin homolog deleted on chromosome 10 (PTEN)/phosphoinositide 3-kinase (PI3K)/Akt pathway (26). The PI3K/AKT/mammalian target of rapamycin (mTOR) pathway is known to be associated with autophagy; however; whether miR-22 is able to regulate the chemosensitivity of OS cell lines (or even drug-resistant cell lines) via the PI3K/AKT/mTOR pathway has yet to be fully elucidated. The present study aimed to further investigate the role of miR-22 in the PI3K/AKT/mTOR pathway in order to explore the effect of miR-22 in CDDP-resistance of OS both in vivo and in vitro.

\section{Materials and methods}

Selection of the cell line. Human osteosarcoma cell lines, including MG63, U2OS, Saos2 and OS9901 (27-30), were obtained from the Cell Bank of the Chinese Academy of Sciences (Shanghai, China). The cells were allowed to proliferate in Hyclone ${ }^{\circledR}$ DMEM medium (HyClone; GE Healthcare Life Sciences) containing 10\% Hyclone ${ }^{\circledast}$ FBS, $100 \mathrm{U} / \mathrm{ml}$ penicillin, and $100 \mu \mathrm{g} / \mathrm{ml}$ streptomycin, and incubated at a temperature of $37^{\circ} \mathrm{C}$ in an atmosphere of $5 \% \mathrm{CO}_{2}$. CDDP $(2 \mu \mathrm{M})$ was added to the cell lines for $24 \mathrm{~h}$. Subsequently, reverse transcription-PCR (RT-PCR) assay was performed to investigate the expression levels of BECN1 and ATG5 in each cell line.

Cell culture and transfection. The drug-resistant cell line (MG63/CDDP) was obtained by plating MG63 cells ( $1 \times 10^{6}$ cells per well) onto a 6 -well plate and adding $2 \mu \mathrm{M}$ CDDP for $24 \mathrm{~h}$. Subsequently, the dead cells were removed by PBS (Nanjing Dongji, China). After the cells had reached $80 \%$ confluency, $2 \mu \mathrm{M}$ CDDP was added again for $24 \mathrm{~h}$. This procedure was repeated until the subsequent addition of CDDP did not lead to any further cell death. The cells that were finally obtained were of the drug-resistant cell line (MG63/CDDP).

Invitrogen ${ }^{\circledR}$ Lipofectamine $^{\mathrm{TM}} 3000$ (Lipo3000; Life Technologies; Thermo Fisher Scientific, Inc.) was used for all transfection assays, according to the manufacturer's protocol. The MG63 and the MG63/CDDP cells were transiently transfected using negative control (NC) or miR-22 mimic at room temperature. Aliquots $(50 \mu \mathrm{l})$ of Gibco ${ }^{\circledR}$ Opti-MEM (Thermo Fisher Scientific, Inc.) were used to dilute $50 \mathrm{nM} \mathrm{NC}$ or mimic; subsequently, the mixture was added to $3 \mu \mathrm{l}$ diluted Lipo3000, prior to further mixing and incubating the mixture for $20 \mathrm{~min}$ at room temperature. Subsequently, the cells were added to a 6-well plate which contained $100 \mu 1$ liposome transfection mixture (Invitrogen; Thermo Fisher Scientific, Inc.). After incubation for $6 \mathrm{~h}$, the medium was replaced by Hyclone ${ }^{\circledR}$ DMEM medium containing $10 \%$ FBS. After $48 \mathrm{~h}$ of incubation, the cells were harvested after a centrifugation step (1,000 rpm, $5 \mathrm{~min}$, room temperature).

The sequences of the NC and miR-22 mimic constructs were as follows. NC: Sense, UUCUCCGAACGUGUCACG UTT and antisense, ACGUGACACGUUCGGAGAATT; miR-22: Sense, AAGCUGCCAGUUGAAGAACUGU and antisense, AGUUCUUCAACUGGCAGCUUUU. The MG63 and MG63/CDDP cell lines stably expressed miR-22 with lentivirus particles.

Cell proliferation assay. The MG63 and MG63/CDDP cell lines, respectively, were cultured in Hyclone ${ }^{\circledR}$ DMEM Complete $^{\mathrm{TM}}$ culture medium containing $10 \% \mathrm{FBS}$ in a cell incu- 
bator containing $5 \% \mathrm{CO}_{2}$ at $37^{\circ} \mathrm{C}$. The plates were inoculated with $100 \mu \mathrm{l}$ of cells ( $5 \times 10^{5}$ cells/ml was added per well), with the cells being added to each well of a 12-well plate. Cells were adherent to the wall of the plate, and transfection with miR-22 and CDDP was allowed to take place for $48 \mathrm{~h}$. After transfection, $2 \mu \mathrm{M}$ CDDP was added. A solution of bromodeoxyuridine (BrdU) (Sigma-Aldrich; Merck KGaA) was made up to a final concentration of $0.03 \mathrm{mg} / \mathrm{ml}$, and $\mathrm{BrdU}$ was subsequently added to the cells at 6 and $12 \mathrm{~h}$ after transfection. The cells were then incubated at $37^{\circ} \mathrm{C}$ for $3 \mathrm{~h}$. The culture solution was removed, and the cells were washed 3 times with PBS (5 min each wash). Paraformaldehyde (4\%, v/v) was used to fix the cells at room temperature for $10 \mathrm{~min}$. The paraformaldehyde was subsequently removed, and the cells were washed 3 times with PBS (5 min each wash). PBS containing $0.5 \%$ Triton X-100 (Alladin) was added, and the membrane was placed on the ice for $10 \mathrm{~min}$. PBS/Triton X-100 was removed, and the membrane was washed 3 times with precooled PBS (5 min each wash). PBS/3\% BSA (Sigma-Aldrich; Merck $\mathrm{KGaA}$ ) was added to seal the membrane at room temperature for $30 \mathrm{~min}$. The BrdU antibody (cat. no. ab8955, Abcam) was diluted in PBS/1\% BSA solution at the ratio of 1:100. After removal of the sealing solution, the primary antibody was added and either incubated at room temperature for $2 \mathrm{~h}$, or at $4^{\circ} \mathrm{C}$ overnight. The secondary antibody [Alexa Fluor 488 donkey anti-mouse $\operatorname{IgG}(\mathrm{H}+\mathrm{L}) 1$; cat. no. ab150105; Abcam] for fluorescence was diluted in PBS-1\% BSA at a ratio of 1:400, and after the PBS-T was removed, the secondary antibody was added to the membrane and incubated for $1 \mathrm{~h}$ in the dark at room temperature. Subsequently, the secondary antibody was removed by washing with PBS. DAPI $(100 \mathrm{ng} / \mathrm{ml})$ was added, and subsequently incubated with the membrane at room temperature in the dark for $10 \mathrm{~min}$. The DAPI was then removed, anti-fluorescence quenching solution (cat. no. P0126; Beyotime Institute of Biotechnology) was added, and the membrane was either placed in the dark at $4^{\circ} \mathrm{C}$, or photographs were directly captured under a fluorescence microscope (magnification, x200; Ts2R; Nikon).

Monodansylcadaverine (MDC) staining. MDC (cat.no. G0170; purchased from Beijing Solarbio Science \& Technology Co., Ltd.), is a marker for autolysosomes, and is used as a tracer for autophagic vesicles. Cells were fixed and incubated with MDC for $30 \mathrm{~min}$ at $37^{\circ} \mathrm{C}$, and subsequently stained with DAPI. An anti-fluorescence quenching slide (to avoid light) was used for the fluorescence study using a confocal fluorescence microscope (LSM710; Zeiss GmbH). Cells were stained with MDC for $30 \mathrm{~min}$ at $37^{\circ} \mathrm{C}$, and subsequently the fluorescence integrated optical density (IOD) values of MDC in each group were measured.

Flow cytometric assay. Detection of changes in the expression levels of the autophagy-related protein, microtubule-associated proteins 1A/1B light chain 3B (LC3), were qualitatively evaluated by flow cytometry (using a BD Calibur flow cytometer; BD Biosciences). Cells were fixed with $4 \%$ paraformaldehyde for a duration of $10 \mathrm{~min}$, followed by three washes with PBS (5 min each wash). PBS/1\% BSA solution was used for preparing a 1:500 dilution of the LC3 antibody. Subsequently, the cells were incubated for $2 \mathrm{~h}$ with the primary antibody (cat. no. ab229327; Abcam) at room temperature. The Alexa Fluor-488 conjugated secondary antibody (cat. no. A11008; Invitrogen; Thermo Fisher Scientific, Inc.) was dissolved in PBS/1\% BSA solution to achieve a 1:400 dilution, and then added to the fixed cells in the dark at room temperature (for $1 \mathrm{~h}$ ). The treated cells were analyzed by flow cytometry on a BD FACS Calibur platform. Changes in cellular fluorescence were detected in the FL1 channel (BD Caliber, FACSCalibur; BD Biosciences).

Inoculation of tumor cells. To obtained the miR-22 overexpressed vector, the pre-miR-22 hairpin was constructed in the pLV6-EF-1Af/puro lentivirus plasmid (Genepharma). The plasmid was co-transfected into $293 \mathrm{~T}$ cells using Lipofectamine 2000 with pG-P1-VSVG, pG-P2-REV, pG-P3-RRE plasmids. After culture for $48 \mathrm{~h}$, the lentivirus particle was harvested and concentrated with lenti-X concentrator according to the manufacturer's procedure (Clontech Laboratories). MG63 and MG63/CDDP cells were plated in a 6 -well plate. After being cultured for $8 \mathrm{~h}$, the lentivirus particles were poured in the plate to transduce cells with a multiplicity of infection (MOI) of 1:50. The stable clones were selected using $1 \mu \mathrm{g} / \mathrm{ml}$ puromycin for about 1 week.

After 7 days of adaptive feeding $\left(26^{\circ} \mathrm{C}, 12 \mathrm{~h}\right.$ of light and $12 \mathrm{~h}$ of darkness every day, $200 \mathrm{ml}$ water per day), 40 male nude mice aged 8 weeks (SCXK2015-0001; Model Animal Research Center of Nanjing University, Nanjing, China) were randomly divided into 8 treatment groups, with 5 mice in each group: i) MG63; ii) MG63+miR-22, iii) MG63+CDDP; iv) MG63+CDDP+miR-22; v) MG63/CDDP; vi) MG63/CDDP+miR-22; vii) MG63/CDDP+CDDP; and viii) MG63/CDDP+CDDP+miR-22. Subcutaneous inoculation of $5 \times 10^{6}(100 \mu \mathrm{l})$ cells in the right flank was performed. The nude mice were fed normally, and after the appearance of small nodules (following 7 days of inoculation), the MG63, MG63+miR-22, MG63/CDDP and MG63/CDDP+miR-22 groups were administered a normal saline injection of $100 \mu \mathrm{l}$ each time, twice per week for 5 weeks. For the MG63+CDDP, MG63+CDDP+miR-22, MG63/CDDP+CDDP and MG63/CDDP+CDDP+miR-22 treatment groups, CDDP was administered at a dose of $2 \mathrm{mg} / \mathrm{kg}$ each time, twice per week for 5 weeks. Animal health and behavior were monitored every day. The dose of pentobarbital administration was $100 \mathrm{mg} / \mathrm{kg}$ and the manner of euthanasia was intraperitoneal injection. Tumor samples were collected after 6 weeks of normal feeding. Tumor volume (V) was calculated according to the formula: $\mathrm{V}=$ length $\mathrm{x}(\text { width })^{2} / 2$.

Treatment with a specific inhibitor of PI3K. The MG63 cells with or without miR-22 transfection were divided into two groups: A control group and an inhibitor group. DMSO at a concentration of $10 \mu \mathrm{M}$ (C6295; Sigma-Aldrich; Merck KGaA) was added to the cells of the control group. Wortmannin at a concentration of $10 \mu \mathrm{M}$ (S2758; Selleck Chemicals) was added to the cells of the inhibitor group. Each group had four treatment subgroups, comprising treatments of MG63, MG63+miR-22, MG63+CDDP and MG63+CDDP+miR-22. Subsequently, RT-quantitative (q)PCR and western blot analysis were performed. 
$R T$-qPCR. Invitrogen TRIzol ${ }^{\circledR}$ reagent (Thermo Fisher Scientific, Inc.) was used to isolate total RNA from cells or tissues, according to the manufacturer's protocol. The PrimeScript RT reagent kit (Takara Biotechnology Co., Ltd.) was used for conversion of RNA into cDNA; the miRNA extraction kit of Guangzhou RiboBio Co., Ltd. was used to achieve the same objective with respect to miRNA. Quantification of transcripts was accomplished by performing RT-qPCR using SYBR Premix Ex Taq (Takara Biotechnology Co., Ltd.)., and the ABI StepOne Plus Real-Time PCR system (Applied Biosystems; Thermo Fisher Scientific, Inc.) was used to perform qPCR using the SYBR-Green PCR Kit (Takara Biotechnology Co., Ltd.). The qPCR protocol consisted of the following steps: a) initial denaturation for $5 \mathrm{~min}$ at $95^{\circ} \mathrm{C}$; and b) 40 cycles involving denaturation at a temperature of $95^{\circ} \mathrm{C}$ for $10 \mathrm{sec}$, followed by annealing and extension at $60^{\circ} \mathrm{C}$ for $34 \mathrm{sec}$. For miR-22 expression in RT-qPCR, U6 was used as the reference gene. These experiments were repeated three times. miR-22 and U6 primers were amplified by a Bulgeloop miRNA RT-qPCR kit (Guangzhou RiboBio Co., Ltd.). Detailed information of the primers employed for the qPCR experiments is shown in Table I, whereas the thermocycling conditions used for the qPCR experiments are shown in Table II.

Western blot analysis. The cells were bathed in pre-chilled PBS and subsequently lysed in $200 \mu 1$ RIPA buffer (Beyotime Institute of Biotechnology) for 30 min duration by keeping the vials on ice. The cell solution was then centrifuged at $13,500 \mathrm{xg}$ at $4^{\circ} \mathrm{C}$ for $5 \mathrm{~min}$. SDS-PAGE (Bio-Rad Laboratories, Inc.) was used to separate the cellular proteins (8\% SDS-PAGE for PI3K, mTOR, p-mTOR and 10\% SDS-PAGE for Akt, p-Akt, GAPDH), followed by blot transfer to a PVDF membrane (EMD Millipore). Each protein sample (30 $\mu \mathrm{g}$ aliquots) was loaded onto the SDS-PAGE gel. Post-blotting, 5\% skimmed milk was used for incubation of the membrane at $4^{\circ} \mathrm{C}$ for $1 \mathrm{~h}$. 5\% BSA-containing TBS/Tween-20 (TBST) solution was used to prepare 1:1,000 dilutions of the primary antibody (see the next paragraph for further details), and this was subsequently incubated with the membrane overnight at $4^{\circ} \mathrm{C}$. The membranes were washed thrice with TBST at room temperature (10 min each wash). The secondary antibody was diluted with TBST (1:5,000 dilution), and the membranes were then incubated with the secondary antibody at room temperature for $1 \mathrm{~h}$, followed by three washes with TBST at room temperature (10 min each wash). The chemiluminescence reaction was carried out using the Tanon chemiluminescence sensor system (Tanon Science and Technology Co., Ltd.). GAPDH was used as the loading control.

The primary antibodies used for western blotting were as follows: Anti-Akt (cat. no. 10176-2-AP; ProteinTech Group, Inc.); anti-phosphorylated (p)-Akt (cat. no. ab81283; Abcam); anti-PI3K (cat. no. ab151549; Abcam); anti-mTOR (cat. no. 20657-1-AP; ProteinTech Group, Inc.); anti-p-mTOR (cat. no. ab84400; Abcam,); and anti-GAPDH (cat. no. 200306-7E4; ZenBio, Inc.). The secondary antibodies used were as follows: HRP goat anti-mouse $\operatorname{IgG}(\mathrm{H}+\mathrm{L})$ (cat. no. A0216, Beyotime Institute of Biotechnology); HRP goat anti-rabbit $\operatorname{IgG}(\mathrm{H}+\mathrm{L})$ (cat. no. A0208; Beyotime Institute of Biotechnology).
Immunohistochemistry. Paraffin sections were placed in an oven at $65^{\circ} \mathrm{C}$ for $2 \mathrm{~h}$, dewaxed to water, and washed with PBS three times ( 5 min each wash). The slices were placed in EDTA buffer, and put into the microwave for repair. Power was cut off after medium fire to boiling, and low fire to boiling at intervals of $10 \mathrm{~min}$. The slices were subsequently placed in $3 \%$ hydrogen peroxide solution (Sinopharm Chemical Reagent Co., Ltd.), and incubated at room temperature for 10 min to block endogenous peroxidase. The slides were then washed three times in PBS (5 min each wash), prior to being treated with 5\% BSA for 20 min after drying. Subsequently, the BSA was removed, and $50 \mu$ l diluted primary antibody (1:100) was applied to cover the tissue of each slice, followed by an incubation overnight at $4{ }^{\circ} \mathrm{C}$. Subsequently, the PBS solution was removed, and 50-100 $\mu \mathrm{l}$ of the secondary antibody was added to each section, also followed by an incubation at $4^{\circ} \mathrm{C}$ for $50 \mathrm{~min}$. Subsequently, 50-100 $\mu 1$ fresh DAB (Sinopharm Chemical Reagent Co., Ltd.) was added to each slice, and the extent of the color development was assessed under a microscope. After the process of color development was complete, the slides were rinsed with distilled water, redyed with hematoxylin, differentiated with $1 \%$ hydrochloric acid alcohol $(1 \mathrm{sec})$, rinsed with tap water, turned back into a blue color upon addition of ammonia, and rinsed with running water. The sections were subjected to a gradient of alcohol (70-100\%) for 10 min, dehydrated and dried; subsequently, xylene (Sinopharm Chemical Reagent Co., Ltd.) was added, and neutral gum (Sinopharm Chemical Reagent Co., Ltd.) was used for sealing.

The antibodies used in the immunohistochemical analyses were as follows: Anti-p-Akt (cat. no. ab81283; Abcam); anti-PI3K (cat. no. ab151549; Abcam); and anti-p-mTOR (cat. no. ab84400; Abcam).

Statistical analysis. Each experiment was performed three times, and the results are shown as the mean \pm standard deviation. SPSS 17.0 software (SPSS, Inc.) was used for statistical analysis. Differences among three or more groups were compared by one-way analysis of variance (ANOVA); Tukey's test was used for comparisons of data between two groups. $\mathrm{P}<0.05$ was considered to indicate a statistically significant difference.

\section{Results}

Transfection of miR-22 is successful. Fig. 1 shows the mRNA expression of miR-22 in each group. The expression of miR-22 in the transfection group was higher than the group without miR-22 transfection $(\mathrm{P}<0.01)$ for all cell lines used. Thus, transfection was successful.

Expression of the autophagy-related genes is highest in the MG63 cells compared with other cell lines. Fig. 2 shows that the expression levels of the autophagy-related genes BECN1 and ATG5 in MG63 cells were significantly higher compared with the other cell lines, including U2OS, Saos2 and OS9901 $(\mathrm{P}<0.01)$. Thus, we selected the MG63 cell line as our experimental cell line.

miR-22 inhibits proliferation of the MG63 and MG63/CDDP cell lines. The results of the cell proliferation experiments are shown in Fig. 3A-C. The BrdU ratio values in the miR-22 
Table I. Detailed information of primers for the qPCR experiments.

\begin{tabular}{llll}
\hline Gene & \multicolumn{1}{c}{ Sense } & \multicolumn{1}{c}{ Antisense } \\
\hline$G A P D H$ & CTTTGGTATCGTGGAAGGACTC & AGTAGAGGCAGGGATGATGT & 133 \\
$P I 3 K$ & GTATCCCGAGAAGCAGGATTTAG & CAGAGAGAGGATCTCGTGTAGAA & 127 \\
$A k t$ & CTTCTATGGCGCTGAGATTGT & GCCCGAAGTCTGTGATCTTAAT & 131 \\
$m T O R$ & GTGGAAACAGGACCCATGAA & CCATTCCAGCCAGTCATCTT & 102
\end{tabular}

qPCR, quantitative polymerase chain reaction; GAPDH, glyceraldehyde 3-phosphate dehydrogenase; PI3K, phosphoinositide 3-kinase; $A k t$, protein kinase $\mathrm{B} ;$ mTOR, mammalian target of rapamycin.

Table II. Thermal conditions used for the qPCR experiments.

\begin{tabular}{lcc}
\hline Temperature & Time (sec) & \\
\hline $95^{\circ} \mathrm{C}$ & 600 & 40 cycles \\
$95^{\circ} \mathrm{C}$ & 5 & \\
$60^{\circ} \mathrm{C}$ & 60 & Melting curve \\
$95^{\circ} \mathrm{C}$ & 15 & \\
$60^{\circ} \mathrm{C}$ & 60 & \\
$95^{\circ} \mathrm{C}$ & 15 &
\end{tabular}

qPCR, quantitative polymerase chain reaction.

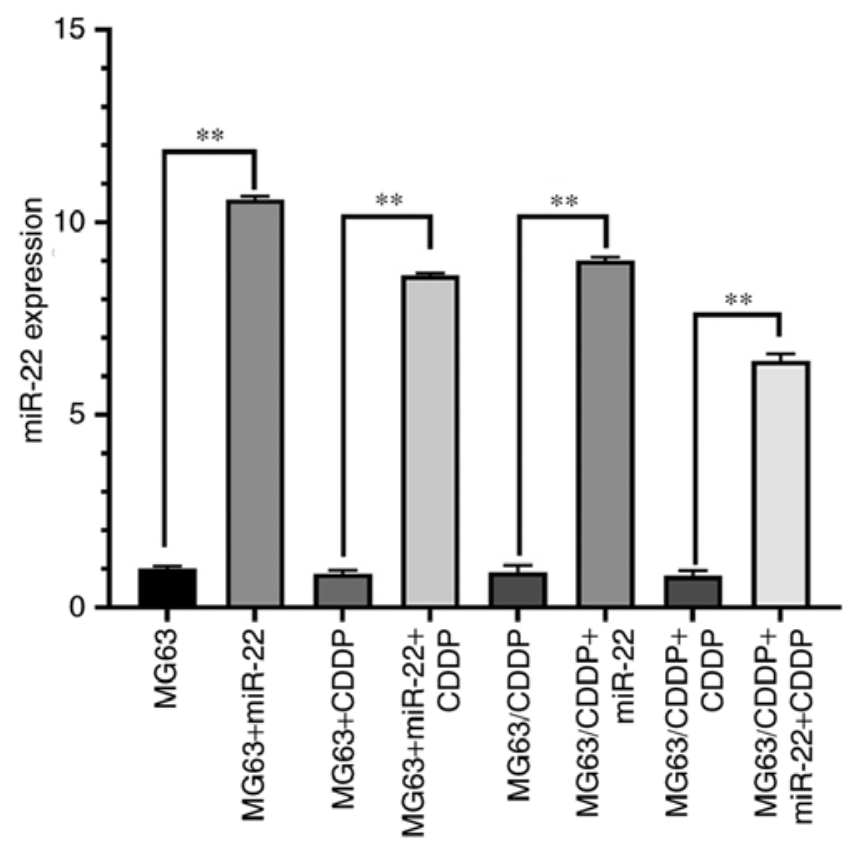

Figure 1. Transfection of miR-22 in each group. MRNA expression of miR-22. ${ }^{* *} \mathrm{P}<0.01$, comparison between the two groups connected with solid lines. CDDP, cisplatin.

group in both the MG63 and MG63/CDDP cell lines were lower than each control group $(\mathrm{P}<0.05)$. Moreover, the values for the miR-22+CDDP treatment group in the two cell lines were lower compared with the respective control groups at the 12 and $24 \mathrm{~h}$ time-points $(\mathrm{P}<0.01)$.
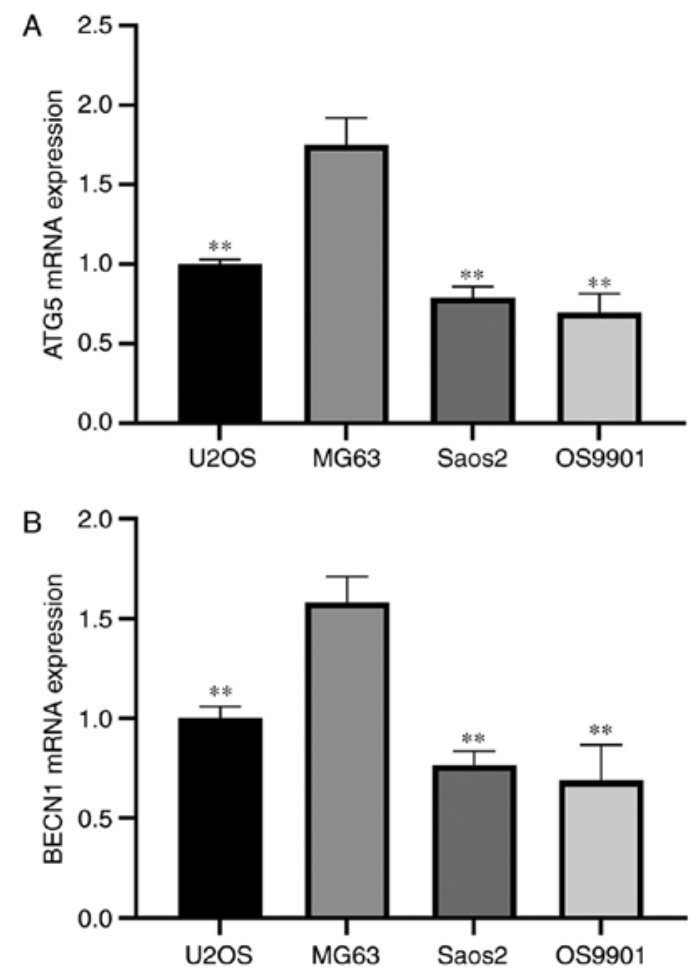

Figure 2. mRNA expression of ATG5 (A) and BECN1 (B) in each cell line treated with CDDP. ${ }^{*} \mathrm{P}<0.05$ and ${ }^{* *} \mathrm{P}<0.01$, compared with the MG63 cells. CDDP, cisplatin; ATG5, autophagy related 5 .

miR-22 suppresses autophagy of the MG63 and MG63/CDDP cell lines. The results of MDC staining are shown in Fig. 4. The autophagy rates were calculated according to the IOD of MDC (Fig. 4C). A higher value of IOD corresponds to a higher autophagy rate. The MG63 cell control group exhibited a lower IOD value compared with the control group of MG63/CDDP cells at the 12 and $24 \mathrm{~h}$ time-point $(\mathrm{P}<0.05)$. The IODs of groups that were transfected by miR-22 for 12 and $24 \mathrm{~h}$ in the MG63 and MG63/CDDP cells were lower when compared with each control group $(\mathrm{P}<0.01)$. Furthermore, the group with combined treatment of miR-22 and CDDP exhibited smaller IOD values compared with the CDDP treatment alone groups of the MG63 and MG63/CDDP cell lines at the times of 12 and $24 \mathrm{~h}(\mathrm{P}<0.01)$.

Flow cytometric assay is used to detect expression of genes in cells by using fluorescent antibodies. In addition, expression of LC3 is associated with autophagy. Moreover, 
A
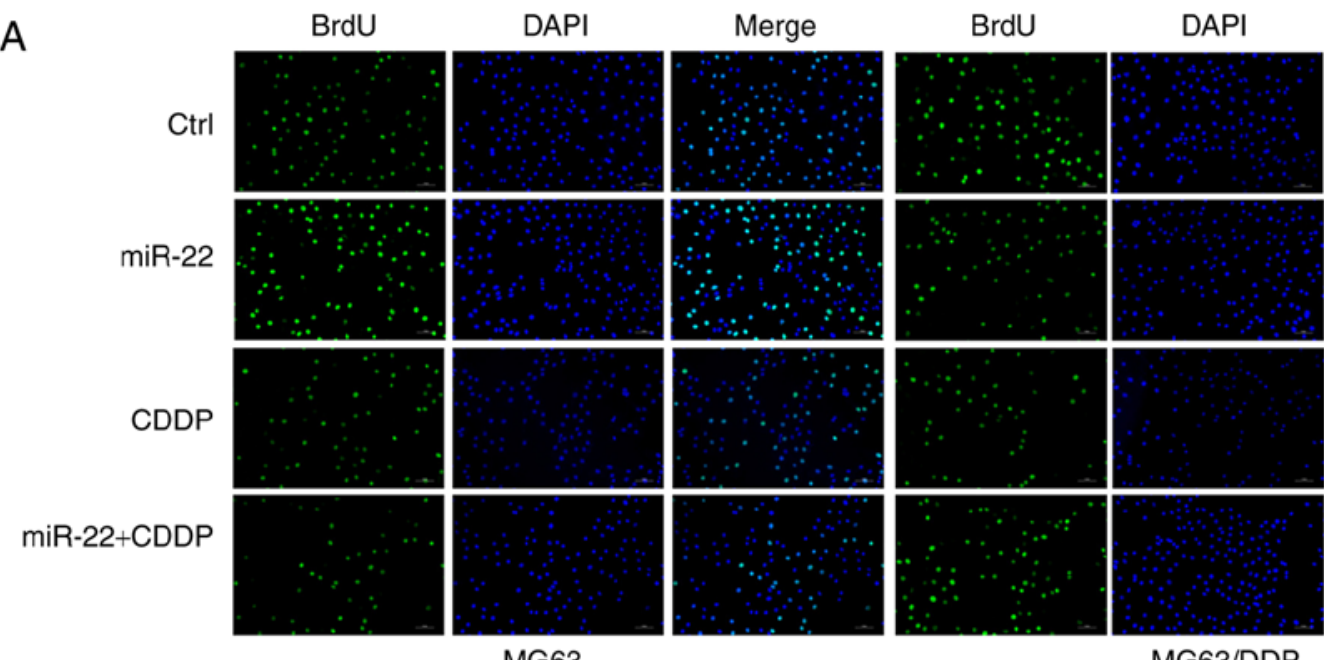

Merge

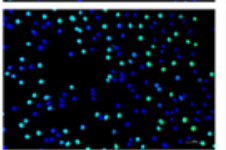

$12 \mathrm{~h}$

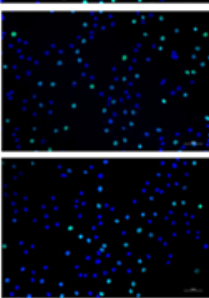

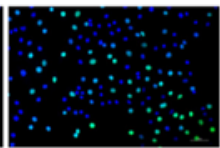

B

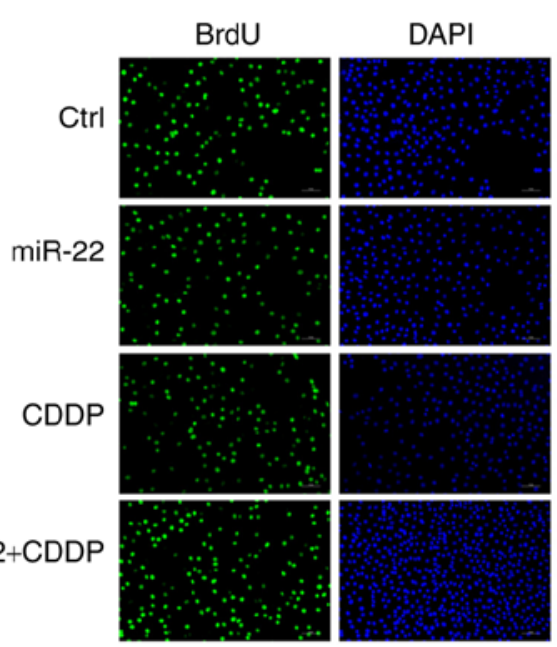

MG63

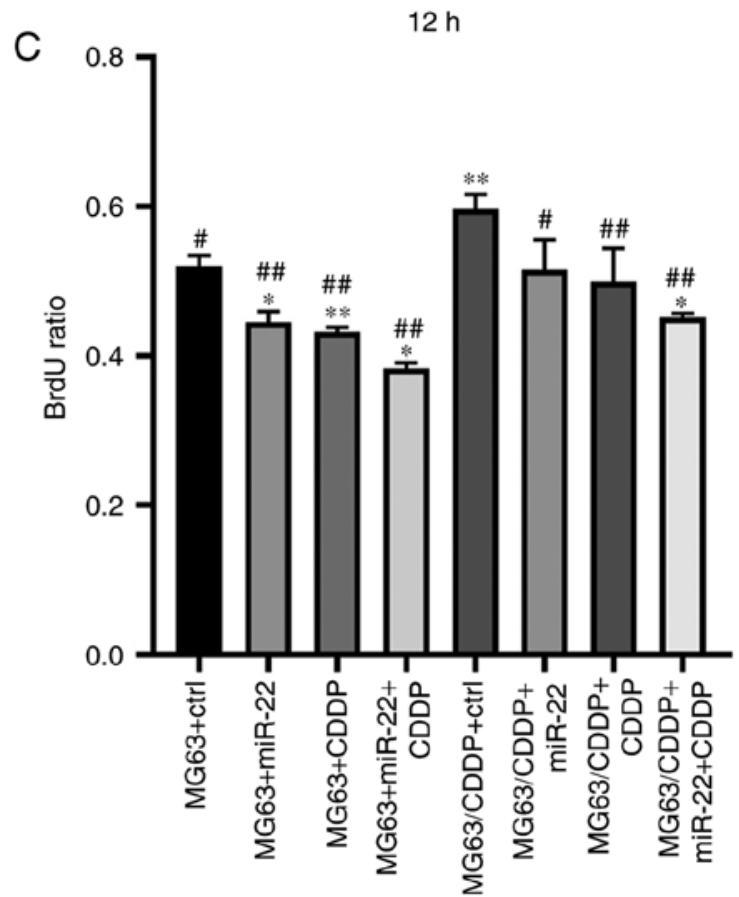

Merge

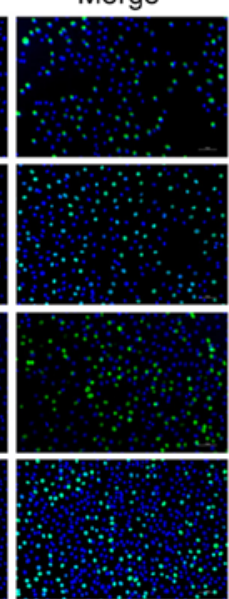

$24 \mathrm{~h}$

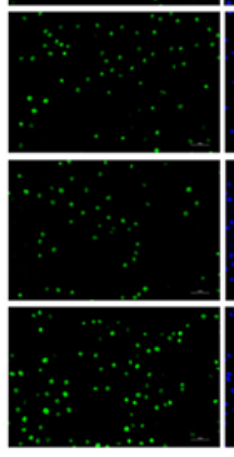

BrdU

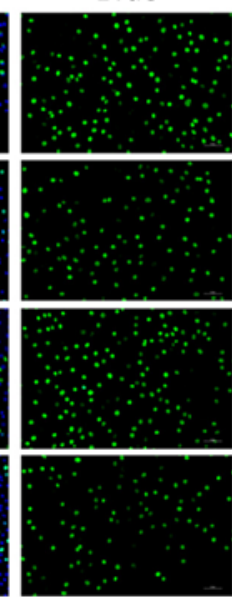

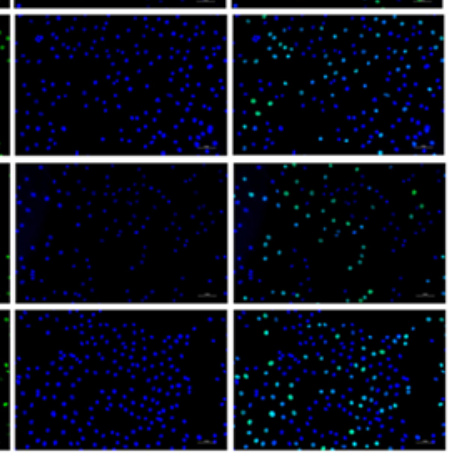

MG63/DDP

DAPI

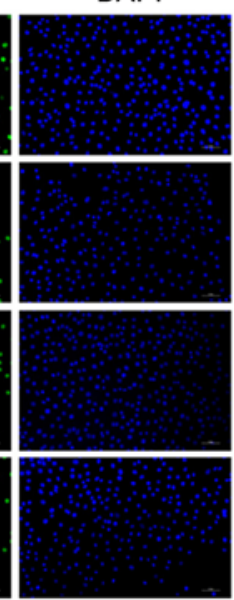

MG63/DDP

$24 \mathrm{~h}$

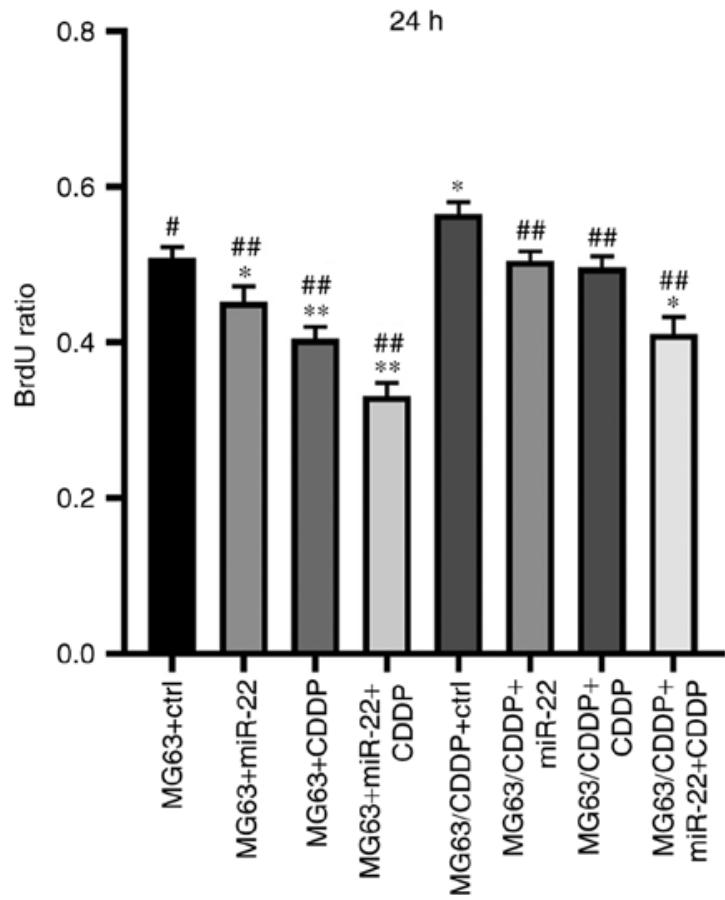

Figure 3. Cell proliferation assay. (A and B) The results of the cell proliferation assay are shown. The results of BrdU staining after transfection for 12 and $24 \mathrm{~h}$. (C) The BrdU ratio values of MG63 and MG63/CDDP cells after transfection for 12 and 24 h. ${ }^{*} \mathrm{P}<0.05$ and ${ }^{* *} \mathrm{P}<0.01$, compared with control group of MG63; ${ }^{\#} \mathrm{P}<0.05$ and ${ }^{\# \#} \mathrm{P}<0.01$, compared with the control group of MG63/CDDP. CDDP, cisplatin; BrdU, bromodeoxyuridine. 
A

DAPI

MDC

Merge

DAPI

MDC

Merge

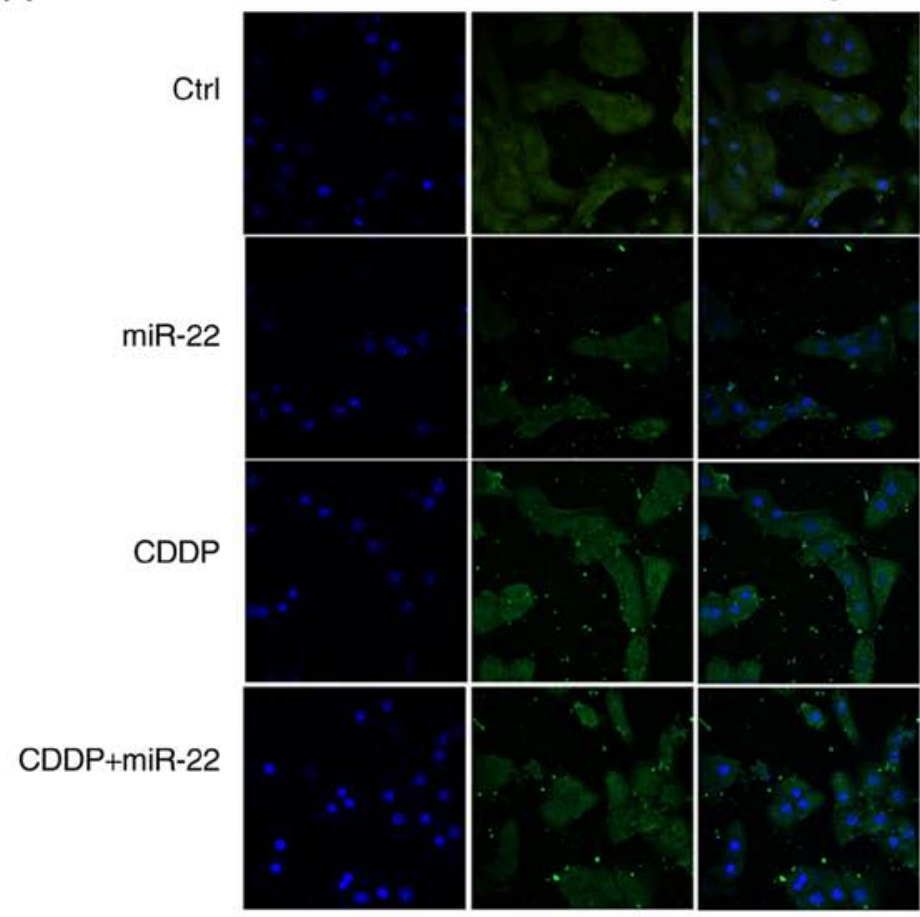

MG63

B

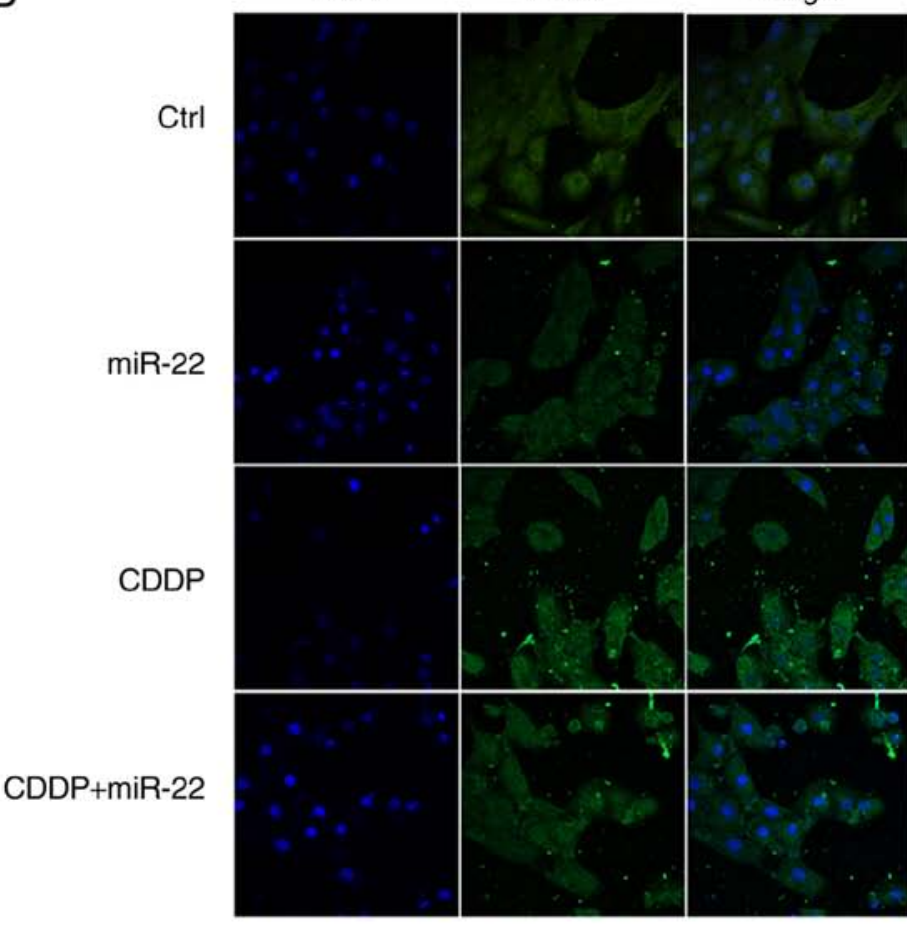

MG63
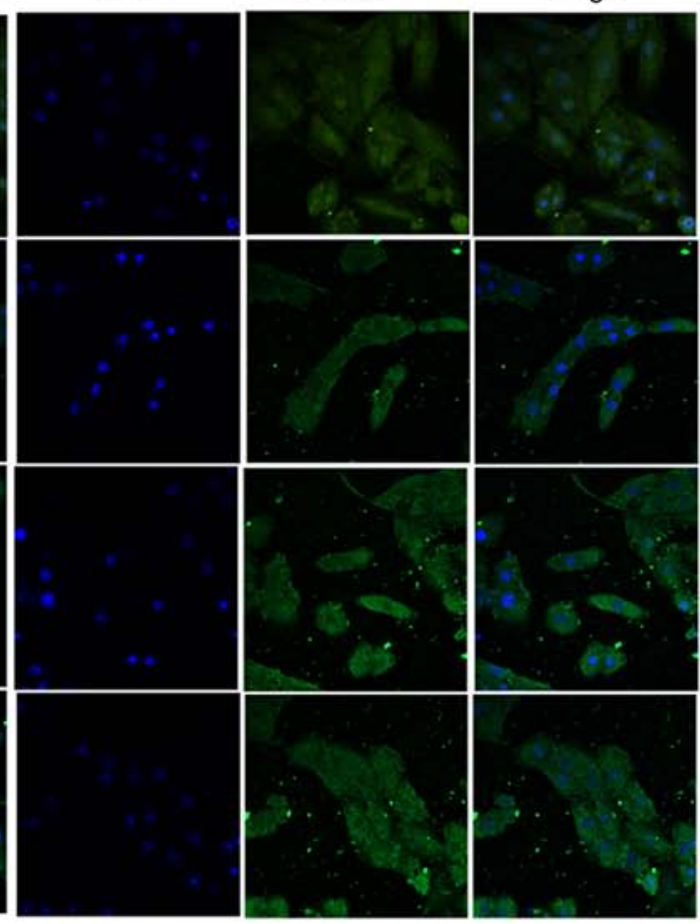

MG63/DDP

$12 \mathrm{~h}$

DAPI

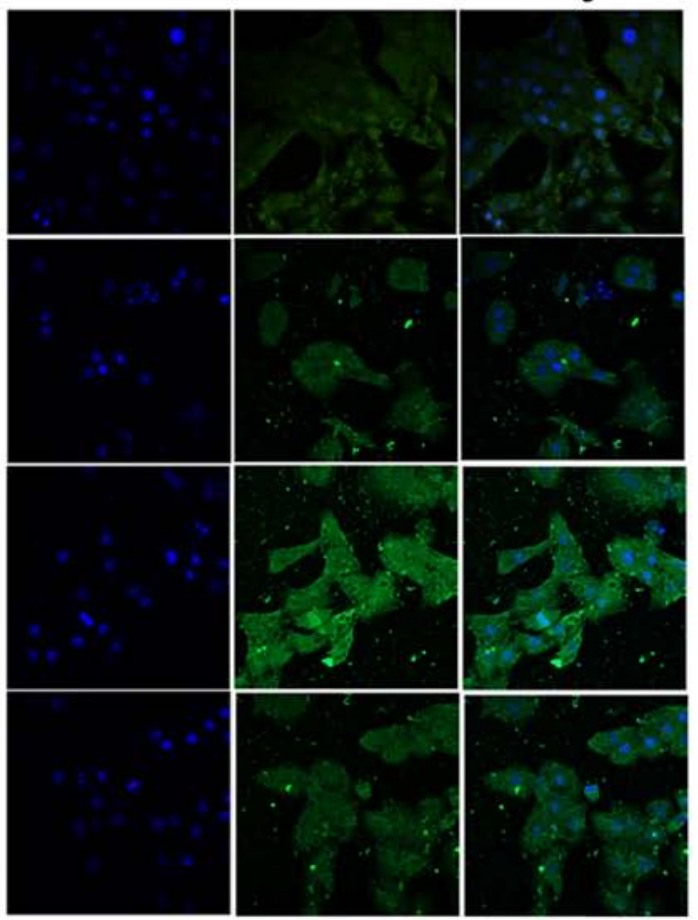

MG63/DDP

$24 \mathrm{~h}$

Figure 4. MDC staining results. (A and B) The MDC staining results after treatment for 12 and $24 \mathrm{~h}$ in MG63 and MG63/CDDP cells. MDC, monodansylcadaverine; CDDP, cisplatin.

the results consolidated to findings which were obtained by measuring LC3B II/LC3B I, MDC staining and electron microscopy observation $(25,31)$. Thus, we performed LC3 flow cytometry to verify autophagy. Fig. 5A-C revealed that the fluorescence values of LC3 in the miR-22 group of the MG63 and MG63/CDDP cell lines were lower compared with each respective control group, whereas the value was higher in the CDDP treatment groups of the two cell lines compared with 

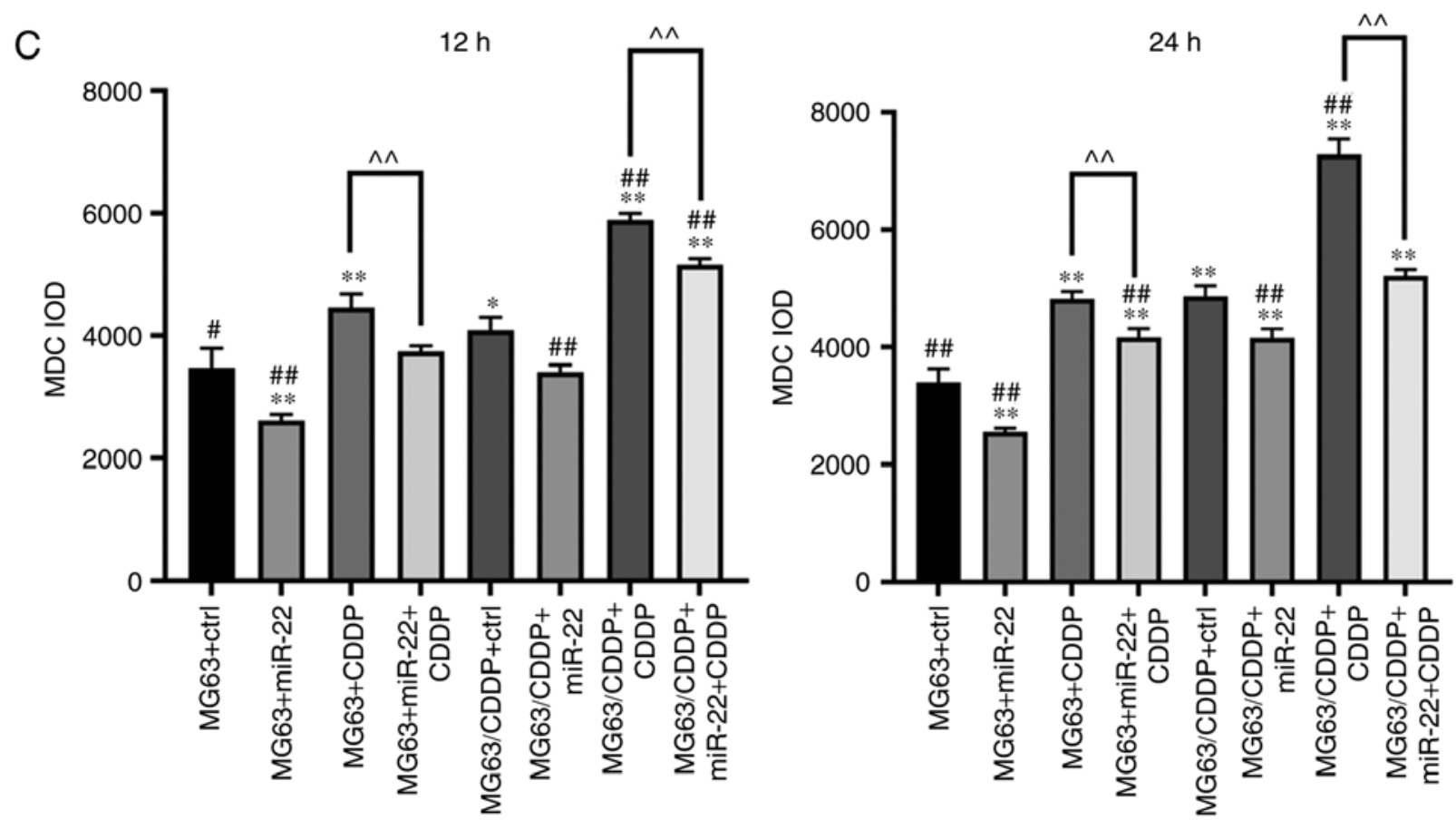

Figure 4. Continued. MDC staining results. (C) The MDC IOD values in each group at the times of 12 and $24 \mathrm{~h}$. " $\mathrm{P}<0.05$ and ${ }^{* *} \mathrm{P}<0.01$, compared with the control group of MG63; ${ }^{P} \mathrm{P}<0.05$ and ${ }^{\# \#} \mathrm{P}<0.01$, compared with the control group of MG63/CDDP; ${ }^{\wedge} \mathrm{P}<0.01$, comparison between the two groups connected with solid lines. MDC, monodansylcadaverine; CDDP, cisplatin.

the control, which revealed that miR-22 inhibited autophagy, whereas CDDP induced autophagy $(\mathrm{P}<0.05)$. Furthermore, miR-22 decreased the level of autophagy that was induced by CDDP in the MG63 and MG63/CDDP cells $(\mathrm{P}<0.01)$. The results obtained from the LC3 flow cytometric assays at the 12 and 24 h time-points were similar.

CDDP induces autophagy of the MG63 and MG63/CDDP cell lines. As shown in Fig. 4C, the IOD values in the CDDP treatment group at times of 12 and $24 \mathrm{~h}$ were higher compared with the control groups for each cell line $(\mathrm{P}<0.01)$. As shown in Fig. 6A-C, the mRNA expression levels of PI3K, Akt and mTOR, and the protein expression levels of PI3K, p-Akt and p-mTOR, were upregulated in MG63/CDDP cells; it was also observed that CDDP could downregulate the expression of these genes in the MG63 and MG63/CDDP cells compared with each control group $(\mathrm{P}<0.05)$. The results obtained following treatment with CDDP for 12 and $24 \mathrm{~h}$ were similar.

miR-22 inhibits tumor growth and increases the anti-proliferative effect of $C D D P$. Images of the tumors are shown in Fig. 7A. The growth curves obtained after inoculating the mice with MG63 cells or MG63/CDDP cells are shown in Fig. 6B. The volume and weight of the tumors are shown in Fig. 7C. The tumors resulting from inoculation of either MG63 cells or MG63/CDDP cells combined with miR-22 and CDDP treatments were shown to have the smallest volume and weight compared with each of the control groups $(\mathrm{P}<0.01)$. Both miR-22 and CDDP were able to inhibit growth of the tumors $(\mathrm{P}<0.01)$. The tumor volumes and weights resulting after inoculation of the mice with the MG63/CDDP cells were larger compared with the tumors resulting from the inoculation of MG63 cells $(\mathrm{P}<0.01)$.
miR-22 downregulates the PI3K/Akt/mTOR pathway to suppress autophagy. As shown in Fig. 8A and B, miR-22 was able to downregulate the expression levels of PI3K, Akt and mTOR in the MG63 and MG63/CDDP cell lines compared with each control group at the mRNA level $(\mathrm{P}<0.05)$. miR-22 also downregulated the expression of PI3K, p-Akt and p-mTOR in the MG63 and MG63/CDDP cell lines compared with each control group at the protein level $(\mathrm{P}<0.05)$. The MG63/CDDP cell line revealed an upregulation of PI3K, p-Akt and p-mTOR compared with the MG63 control group, whereas both miR-22 and CDDP were able to inhibit the upregulation of these genes $(\mathrm{P}<0.05)$.

The immunohistochemical results are shown in Fig. 9A-D. The IOD values of each gene are shown in Fig. 9D. The control group of the MG63/CDDP cells was found to have a higher PI3K IOD value compared with that of control group of the MG63 cell line $(\mathrm{P}<0.05)$. The expression levels identified in the CDDP and the miR-22 group were low for both of the both cell lines compared with each control group $(\mathrm{P}<0.05)$. The control group of the MG63/CDDP cells exhibited a higher $\mathrm{p}$-Akt IOD value compared with that of the MG63 cells $(\mathrm{P}<0.05)$. The expression of $\mathrm{p}-\mathrm{Akt}$ in the CDDP and miR-22 groups was downregulated in both the cell lines compared with each control group $(\mathrm{P}<0.05)$. In addition, the expression of the other groups compared with each control group was downregulated $(\mathrm{P}<0.05)$. The control group of the MG63/CDDP cells was shown to have a higher $\mathrm{p}-\mathrm{mTOR}$ IOD value compared with that of the MG63 cells $(\mathrm{P}<0.05)$. Treatment with CDDP and miR-22 in the MG63 and MG63/CDDP cells led to lower IOD values compared with each control group $(\mathrm{P}<0.05)$. In addition, combined treatment with CDDP and miR-22 led to lower values compared with each control group $(\mathrm{P}<0.01)$. 

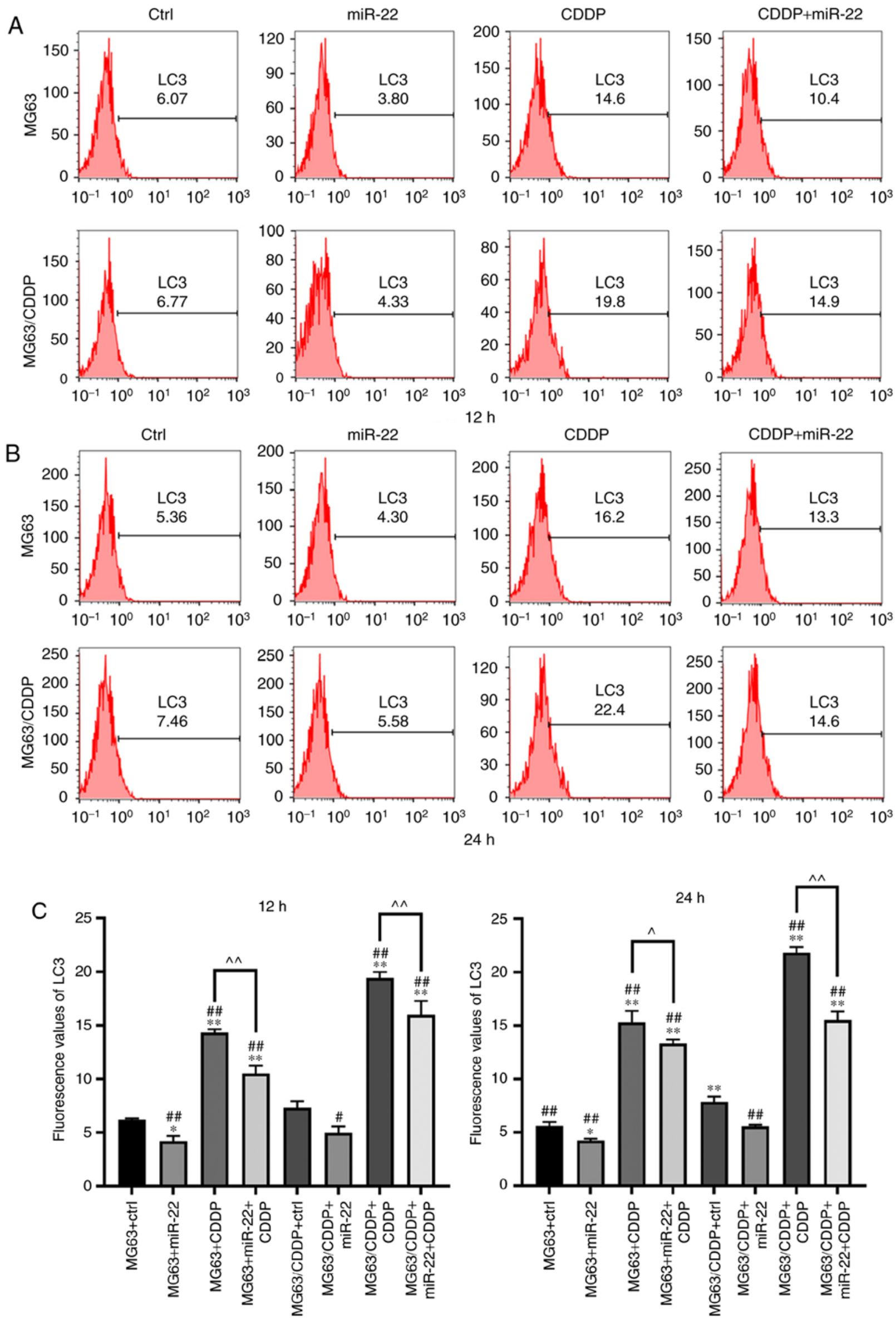

Figure 5. Flow cytometric analysis. (A and B) The flow cytometric analysis of LC3 after transfection for 12 and 24 h. (C) The fluorescence values of LC3 expression after transfection for 12 and $24 \mathrm{~h}$. ${ }^{*} \mathrm{P}<0.05$ and ${ }^{* *} \mathrm{P}<0.01$, compared with the control group of $\mathrm{MG} 63$; ${ }^{*} \mathrm{P}<0.05$ and ${ }^{\# \#} \mathrm{P}<0.01$, compared with the control group of MG63/CDDP; ${ }^{\wedge} \mathrm{P}<0.05$ and ${ }^{\wedge} \mathrm{P}<0.01$, comparison between the two groups connected with solid lines. CDDP, cisplatin. 
A
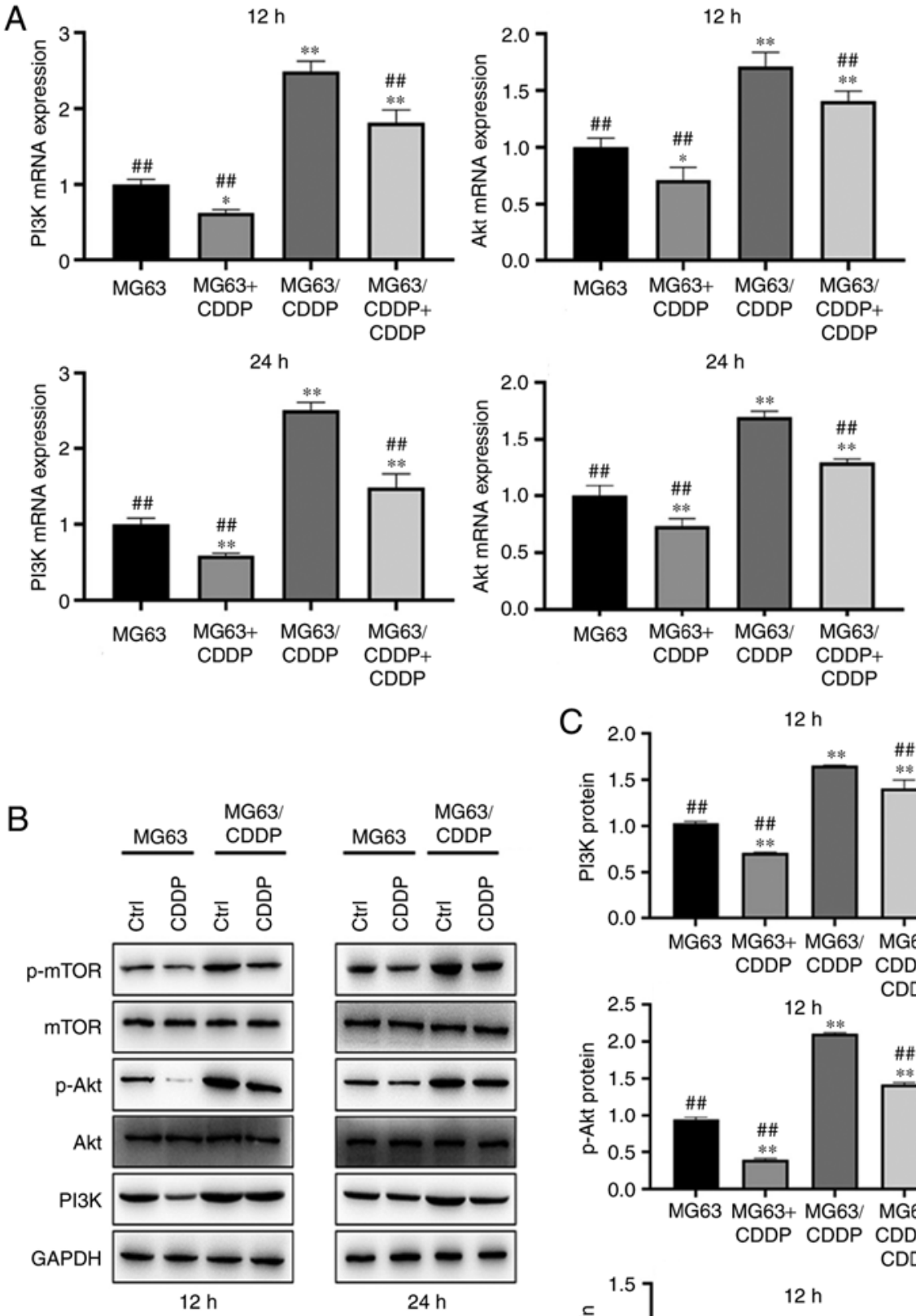

C
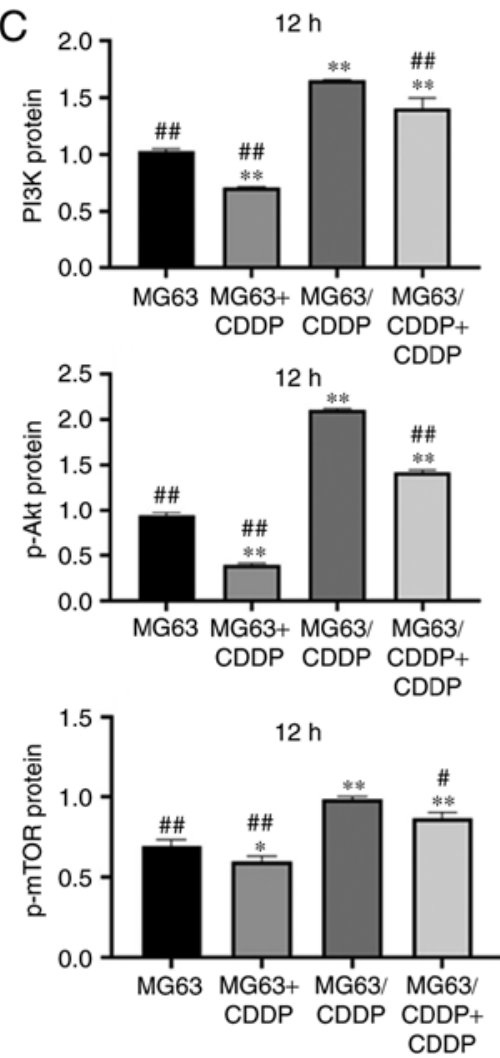

$12 \mathrm{~h}$

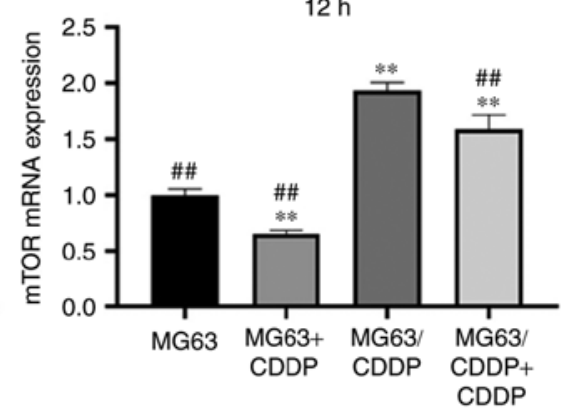

$24 \mathrm{~h}$

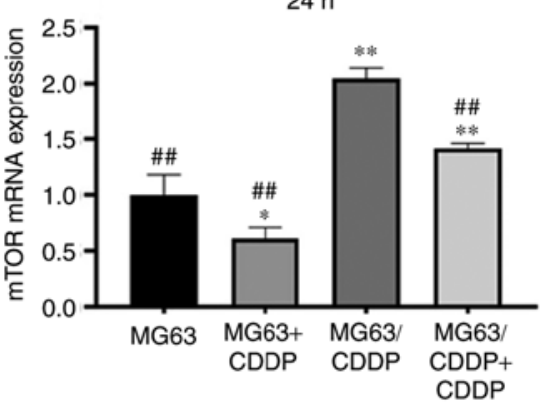

$24 \mathrm{~h}$
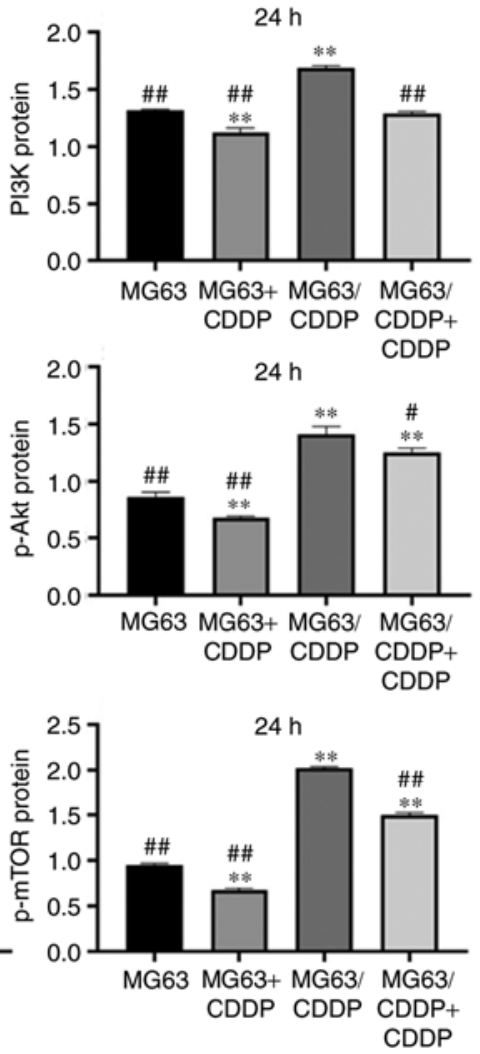

Figure 6. (A) mRNA expression of PI3K, Akt and mTOR following treatment with CDDP for 12 and 24 h. (B) Protein expression of mTOR, p-mTOR, Akt, p-Akt and PI3K after treatment with CDDP for 12 and $24 \mathrm{~h}$, followed by western blot analysis. (C) Protein expression of PI3K, p-Akt and p-mTOR after treatment with CDDP for 12 and $24 \mathrm{~h} .{ }^{*} \mathrm{P}<0.05$ and ${ }^{* *} \mathrm{P}<0.01$, compared with the control group of MG63; ${ }^{\#} \mathrm{P}<0.05$ and ${ }^{\# \#} \mathrm{P}<0.01$, compared with the control group of MG63/CDDP. To determine the extent of phosphorylation of Akt, the value shown for p-Akt is the ratio of the IODs of p-Akt and Akt; for p-mTOR, the extent of phosphorylation of mTOR is shown as the ratio of the IODs of p-mTOR and mTOR. PI3K, phosphoinositide 3-kinase; mTOR, mammalian target of rapamycin; p-, phosphorylated; CDDP, cisplatin; IOD, integrated optical density.

Role exerted by miR-22 is similar to that of wortmannin, a specific inhibitor of $P I 3 K$, in terms of regulating the PI3K/Akt/mTOR pathway. Fig. 10A and B show that the expression levels of LC3 (LC3II/I for protein expression), PI3K, Akt and mTOR in the MG63 cells were downregulated in the wortmannin-treated group compared with the DMSO group at both the mRNA and protein level $(\mathrm{P}<0.05)$ while the expression of p62 was upregulated $(\mathrm{P}<0.01)$. These results suggested that wortmannin could suppress the PI3K/Akt/mTOR pathway and autophagy. In addition, in the CDDP-treated cells, the expression levels of PI3K, Akt and mTOR were downregulated in the wortmannin group compared with the DMSO group at both the 
A
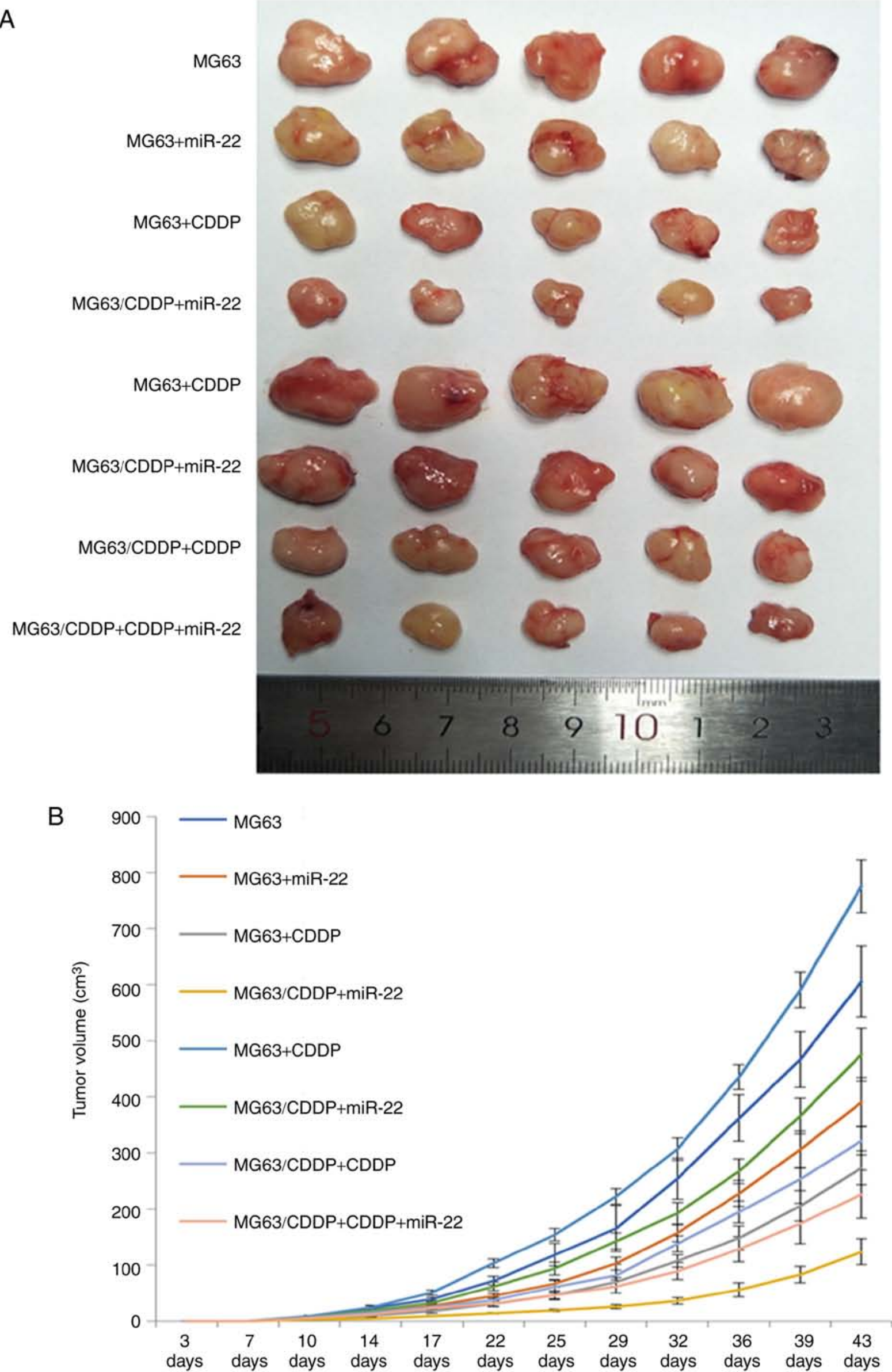

Figure 7. Results of the in vivo experiments. (A) Appearance of the tumors. (B) The growth curve after inoculation with the MG63 and the MG63/CDDP cells. (CDDP, cisplatin. 
C

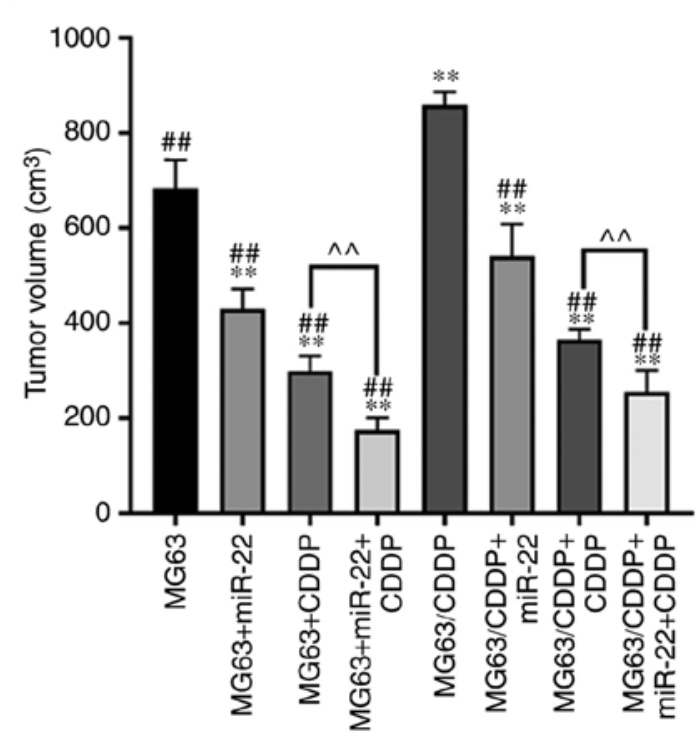

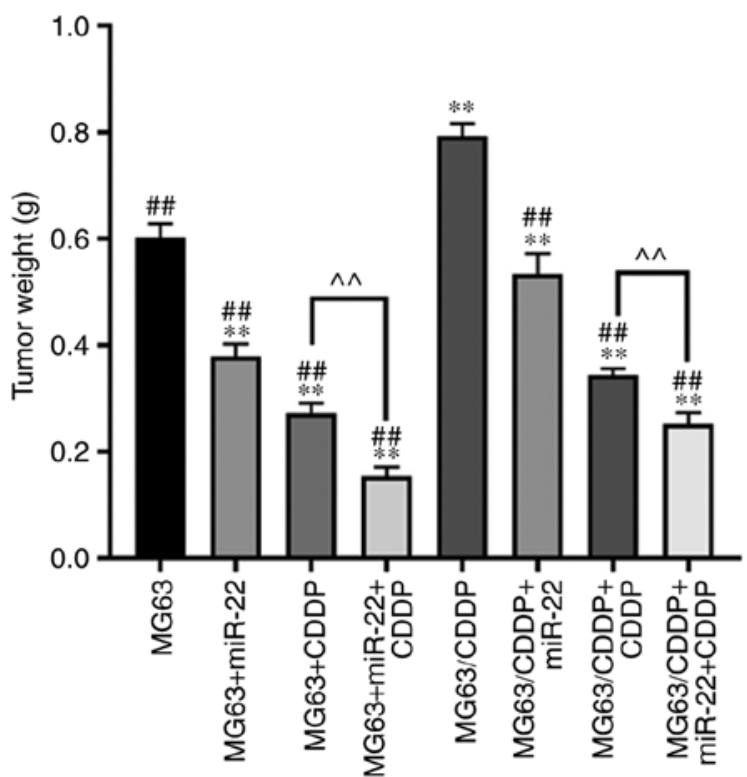

Figure 7. Continued. Results of the in vivo experiments. (C) The volume and weight of tumors after inoculation with MG63 and MG63/CDDP cells. * $<<0.05$ and ${ }^{* *} \mathrm{P}<0.01$, compared with the control group of MG63 cells; ${ }^{\#} \mathrm{P}<0.05$ and ${ }^{\# \#} \mathrm{P}<0.01$, compared with the control group of MG63/CDDP cells; ${ }^{\wedge} \mathrm{P}<0.01$, comparison between the two groups connected with solid lines. CDDP, cisplatin.

mRNA and the protein level $(\mathrm{P}<0.05)$. In addition, the expression of p62 in both mRNA and protein level was upregulated in the MG63+CDDP+wortmannin group compared with the MG63+ CDDP+DMSO group while LC3 was downregulated $(\mathrm{P}<0.01)$. These results suggested that, in MG63 cells that has been treated with CDDP, the role of miR-22 was similar to that of wortmannin in terms of regulating the PI3K/Akt/mTOR pathway and autophagy. In addition, when applied to the miR-22+MG63 group, wortmannin upregulated the expression of p62 and downregulated the expression of LC3, PI3K, Akt and mTOR at both the mRNA and protein level compared with the DMSO-treatment group $(\mathrm{P}<0.05)$, which suggest that inhibitors of PI3K are able to enhance the effects elicited by miR-22.

\section{Discussion}

Chemoresistance may be regulated in numerous ways, mediated via drug export transporters, DNA repair mechanisms, cancer stem cells, resistance to apoptosis, self-sufficiency for growth factor signaling, angiogenic switch, and immunological pathways (32). Autophagy has been found to be closely associated with chemoresistance. On one hand, autophagy directs damaged components of the cells within autophagosomes and ensures their removal, helping to maintain cellular homeostasis. In addition, autophagy is able to protect cells by maintaining a balance among the synthesis, degradation, and subsequent recycling of essential molecules under the condition of nutrient deprivation $(33,34)$. On the other hand, autophagy may induce cell death under the condition of an excessive loss of proteins (35). Therefore, autophagy is considered to be a 'double-edged sword'. It has been shown that overexpression of miR-155 promoted autophagy induced by anticancer drugs, and also increases cell viability to modulate drug resistance in OS cells (36). However, in the majority of the studies that have been published on chemoresistance associated with OS treatment, inhibition of autophagy led to a reduction in drug resistance and an improvement in cell sensitivity $(37,15)$. In the present study, it was shown that miR-22 inhibited the proliferation of cells, including the MG63 and MG63/CDDP cell lines. Furthermore, miR-22 was able to corroborate the effect of CDDP in terms of fulfilling its anti-proliferative role. In addition, the results of the present study confirmed that miR-22 regulates chemoresistance by suppressing autophagy, and suppression of autophagy, in turn, reduces the resistance to CDDP in both MG63 and MG63/CDDP cells.

In the in vivo study, the results obtained followed the identical trend to those of the in vitro study. Following inoculation of the tumor cells, the tumor volumes were observed to be comparatively small in the MG63+CDDP+miR-22 group, which indicates that miR-22 was able to increase the cell sensitivity to CDDP. In the MG63/CDDP+miR-22 group, the tumor volumes were smaller compared with the MG63/CDDP treatment group, which suggested that miR-22 decreased the resistance associated with CDDP. In the present study, it was shown that CDDP upregulated autophagy, which, in turn, may have increased the resistance of CDDP. However, miR-22 not only inhibited autophagy in tumor cells, but it also inhibited the CDDP-induced autophagy. It has been reported that autophagy can contribute to increased levels of chemoresistance in cancer; however, it also contributes to the inhibition of chemoresistance in certain types of cancer $(32,38)$. In the present study, our results showed that CDDP could induce autophagy, and therefore it could be hypothesized that CDDP resistance in OS could be acquired by activating autophagy. It was also possible to surmise that resistant tumor cells (of the MG63/CDDP cell line) could acquire chemoresistance through autophagy to protect the cells from the toxic effects of CDDP, even though CDDP could induce autophagy, and autophagy was upregulated in the resistant cells. The present study further confirmed that miR-22 inhibited autophagy in the resistant OS cells, and therefore miR-22 could fulfill roles in decreasing the proliferation, and in inhibiting the growth, of tumor cells. 

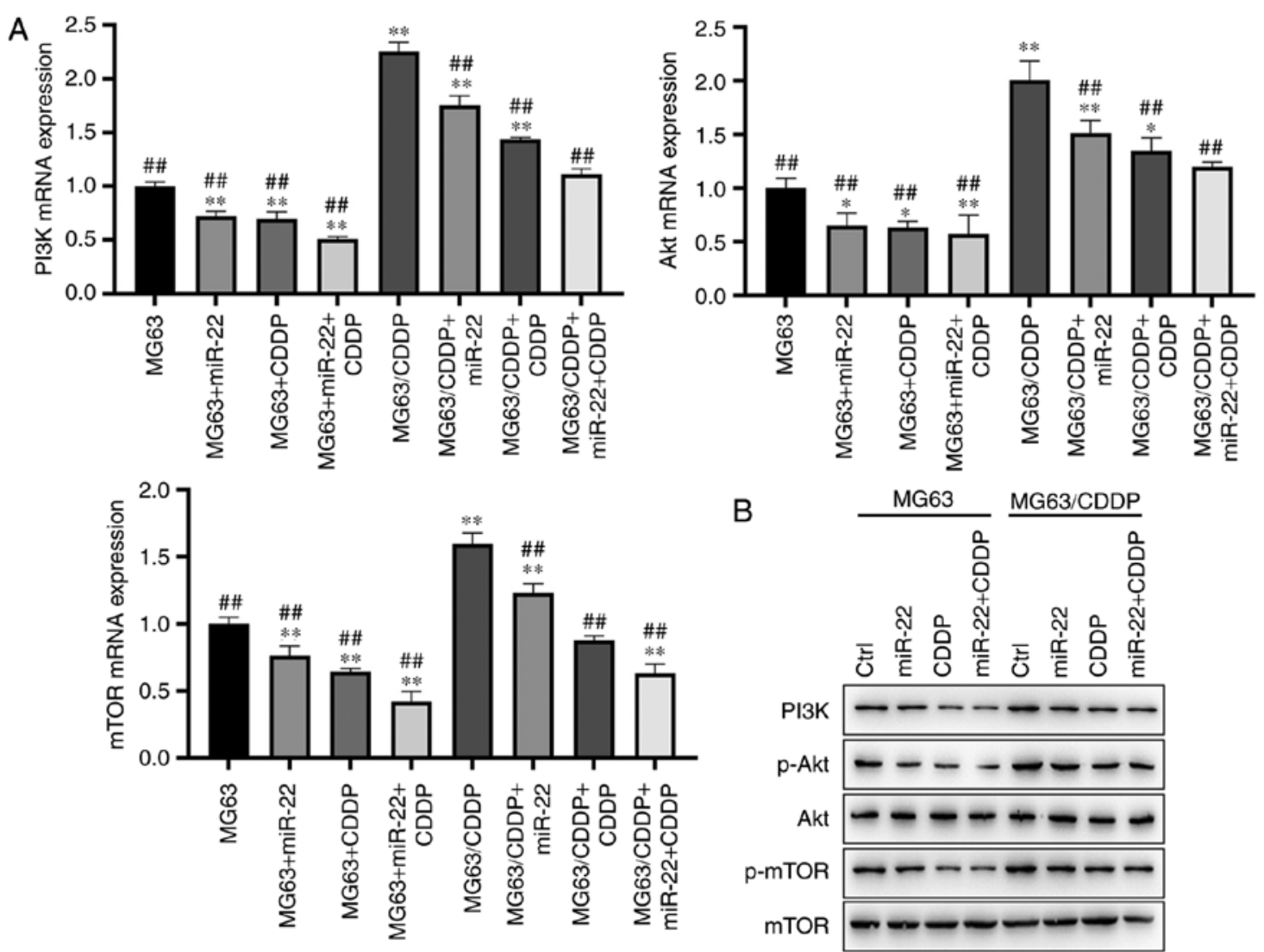

B
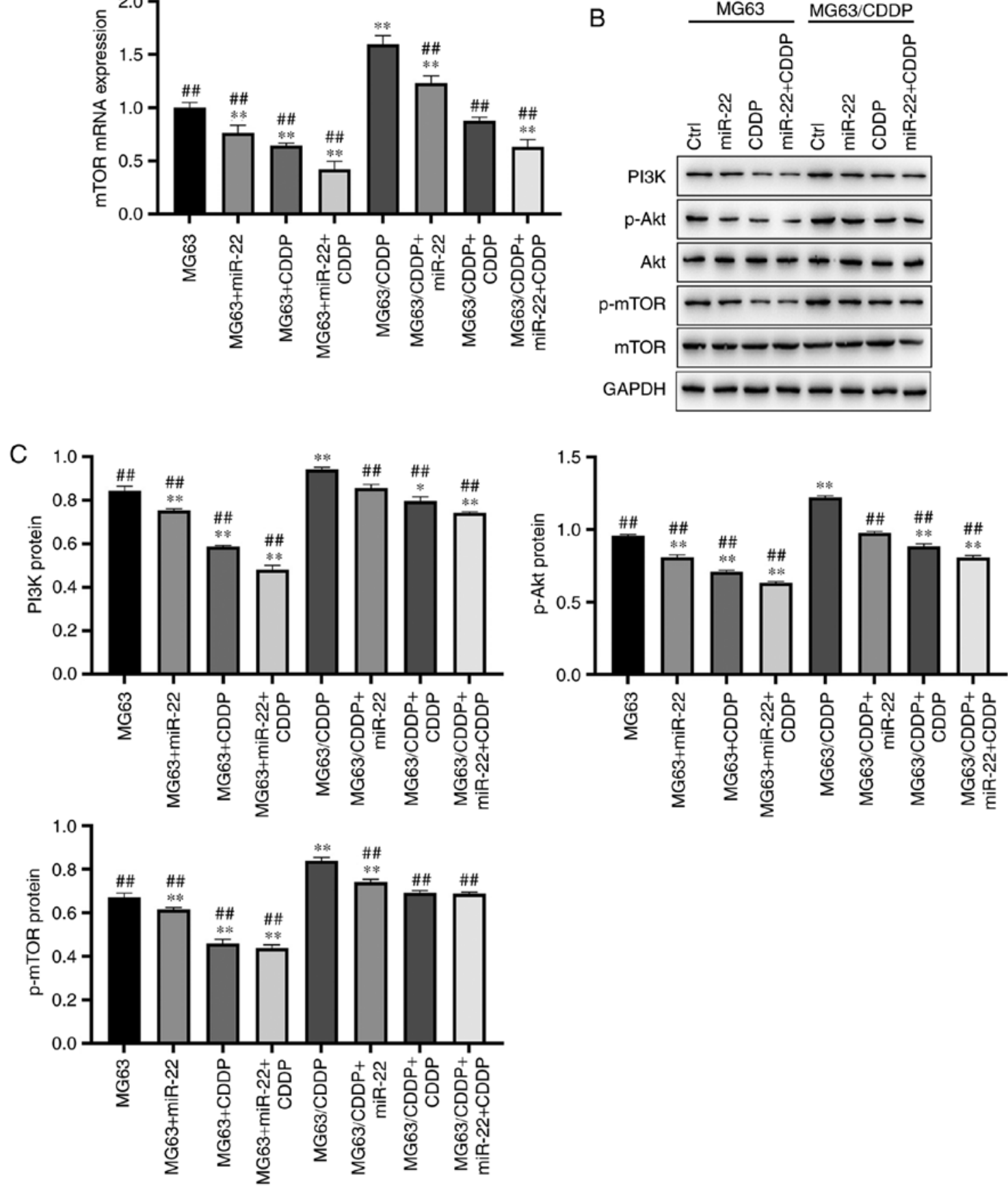

Figure 8. Protein expression levels of PI3K, Akt and mTOR in the MG63 and MG63/CDDP cell lines. (A) mRNA expression of PI3K, Akt and mTOR. (B and C) Protein expression of PI3K, p-Akt and p-mTOR as determined by western blot analysis. ${ }^{\text {" }} \mathrm{P}<0.05$ and ${ }^{* *} \mathrm{P}<0.01$, compared with the control group of MG63; ${ }^{\# \#} \mathrm{P}<0.01$, compared with the control group of MG63/CDDP. To determine the extent of phosphorylation of Akt, the value shown for $\mathrm{p}-\mathrm{Akt}$ is the ratio of the IODs of p-Akt and Akt; for p-mTOR, the extent of phosphorylation of mTOR is shown as the ratio of the IODs of p-mTOR and mTOR. PI3K, phosphoinositide 3-kinase; mTOR, mammalian target of rapamycin; p-, phosphorylated; CDDP, cisplatin; IOD, integrated optical density. 


\section{A}
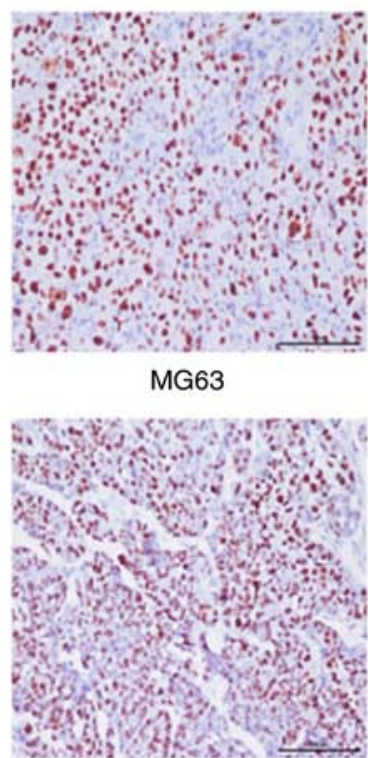

MG63/CDDP

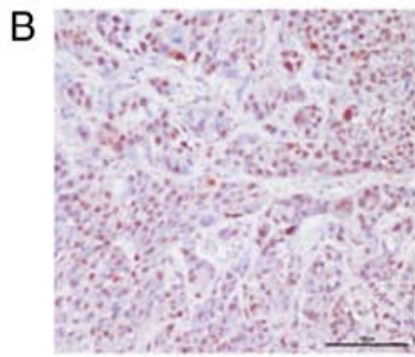

MG63

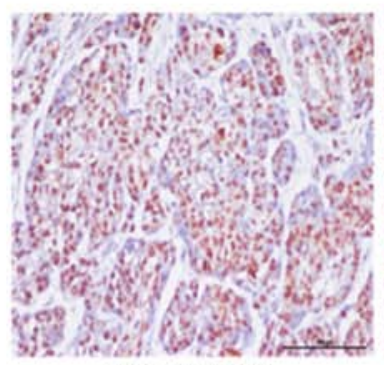

MG63/CDDP

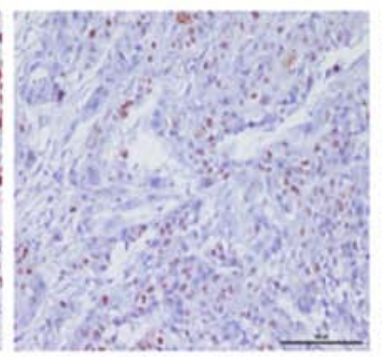

MG63+miR22

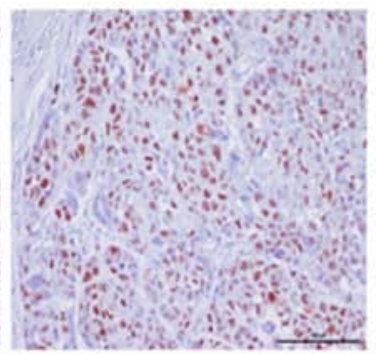

MG63/CDDP+miR22

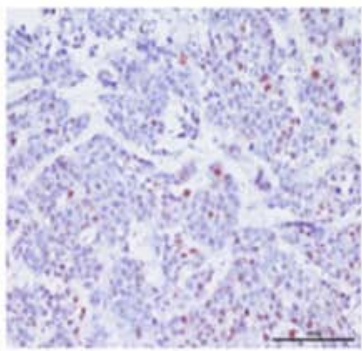

MG63+CDDP

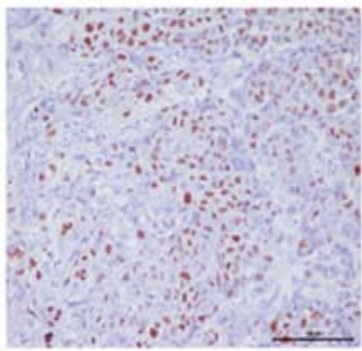

MG63/CDDP+CDDP

$x 200$

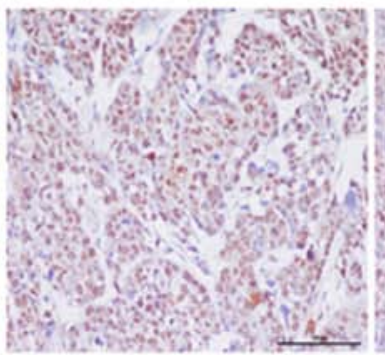

MG63+miR22

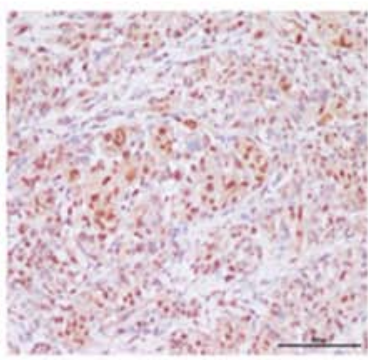

MG63/CDDP+miR22

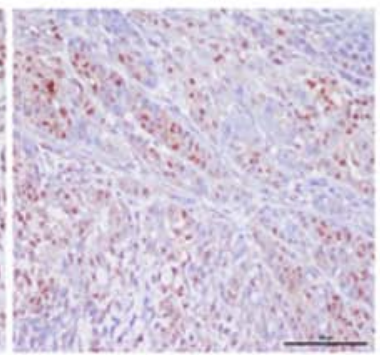

MG63+CDDP

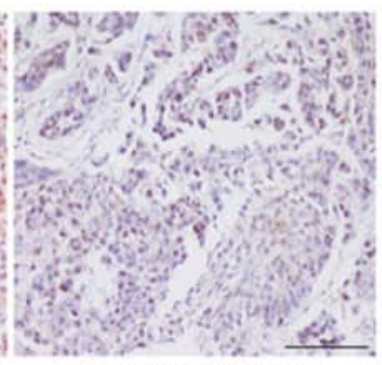

$\mathrm{MG} 63 / \mathrm{CDDP}+\mathrm{CDDP}$

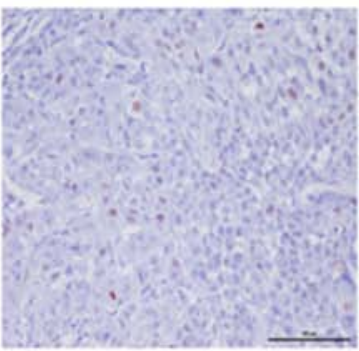

MG63+CDDP+miR22

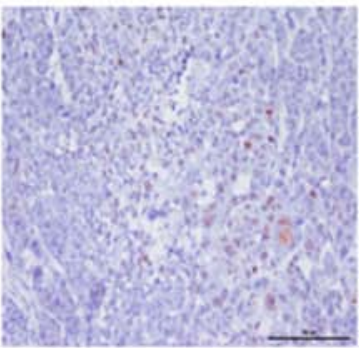

$\mathrm{MG} 63 / \mathrm{CDDP}+\mathrm{CDDP}+\mathrm{miR}-22$

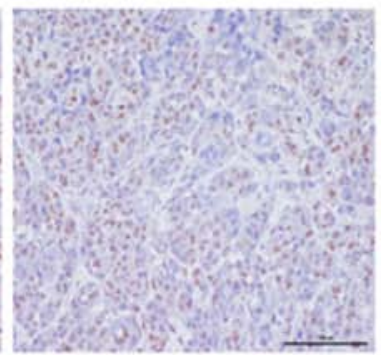

MG63+CDDP+miR22

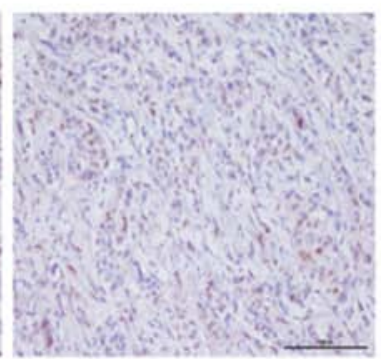

$\mathrm{MG} 63 / \mathrm{CDDP}+\mathrm{CDDP}+\mathrm{miR}-22$

x200

Figure 9. Immunohistochemistry results. Immunohistochemical results of (A) PI3K and (B) p-Akt are shown. PI3K, phosphoinositide 3-kinase; mTOR, mammalian target of rapamycin; p-, phosphorylated; CDDP, cisplatin; IOD, integrated optical density.

Previous studies have investigated the role of miR-22 in chemoresistance in OS treatment. It was previously reported that miR-22 targets the gene $H M G B 1$ to suppress autophagy, leading to a reduction in the levels of adriamycin and CDDP resistance $(23,24)$. Another recently published study demonstrated that miR-22 suppressed the proliferation, and promote the sensitivity, of OS cells via metadherin $(M T D H)$-mediated autophagy (25). The PI3K/Akt/mTOR pathway is an important pathway that regulates autophagy. It has been reported that the PI3K pathway contributes to the growth of cancer cells by providing basic metabolites through glycolysis and lipogenesis (39). In the present study, we found that wortmannin as a specific inhibitor of PI3K inhibited autophagy by regulating the PI3K/Akt/mTOR pathway. Moreover, the role of miR-22 was similar to wortmannin in the MG63 cells and inhibitors of PI3K were able to enhance the effects elicited by miR-22. In addition, a recent study proposed the hypothesis that inhibition of autophagy by suppressing the PI3K/Akt/mTOR pathway by overexpression of HSP90AA1 could decrease drug resistance in OS (40). It has been shown that the proliferation and survival of melanoma are associated with PI3K/Akt (41). In addition, the growth of tumor cells, such as breast cancer cells, could be promoted by mTOR-mediated mitochondrial biogenesis and function (42). Therefore, the downregulation of PI3K, Akt and mTOR is advantageous to anticancer treatment. It has been reported that $\mathrm{PI} 3 \mathrm{~K}$ is the key component of the pathway in terms of activating mTOR-induced autophagy (43). In addition, CDDP treatment inactivated the $\mathrm{PI} 3 \mathrm{~K} / \mathrm{AKT} / \mathrm{mTOR}$ signaling pathway to 


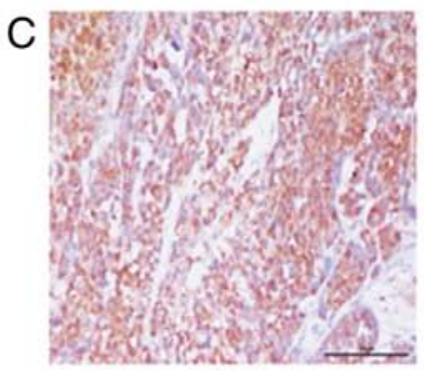

MG63

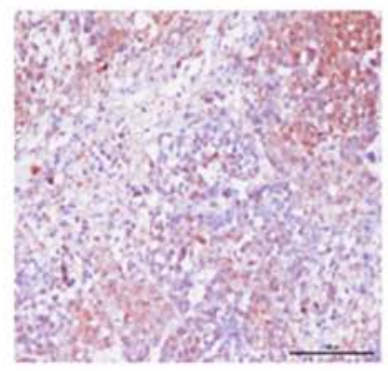

MG63/CDDP

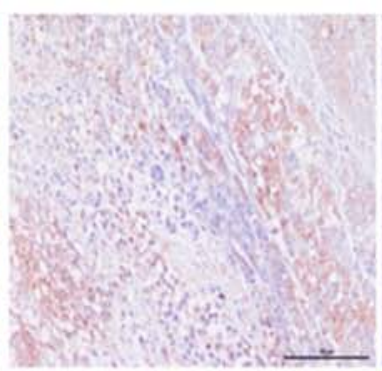

MG63+miR22

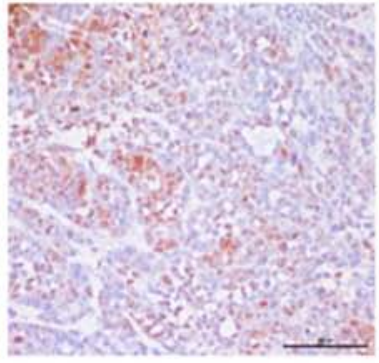

MG63/CDDP+miR22

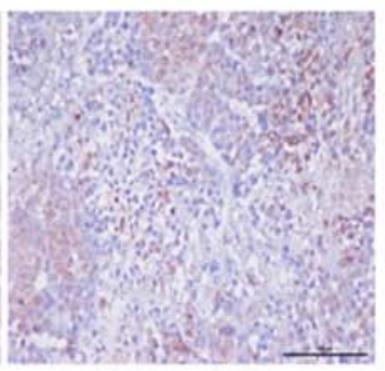

MG63+CDDP

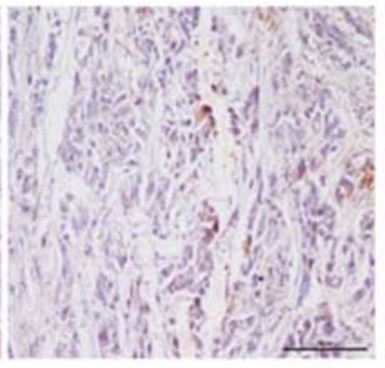

$\mathrm{MG} 63 / \mathrm{CDDP}+\mathrm{CDDP}$

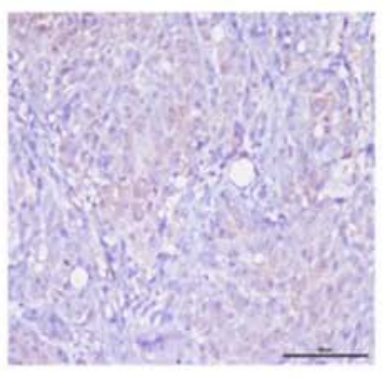

MG63+CDDP+miR22

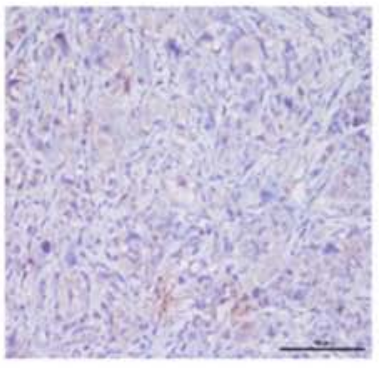

MG63/CDDP+CDDP+miR-22

$200 x$
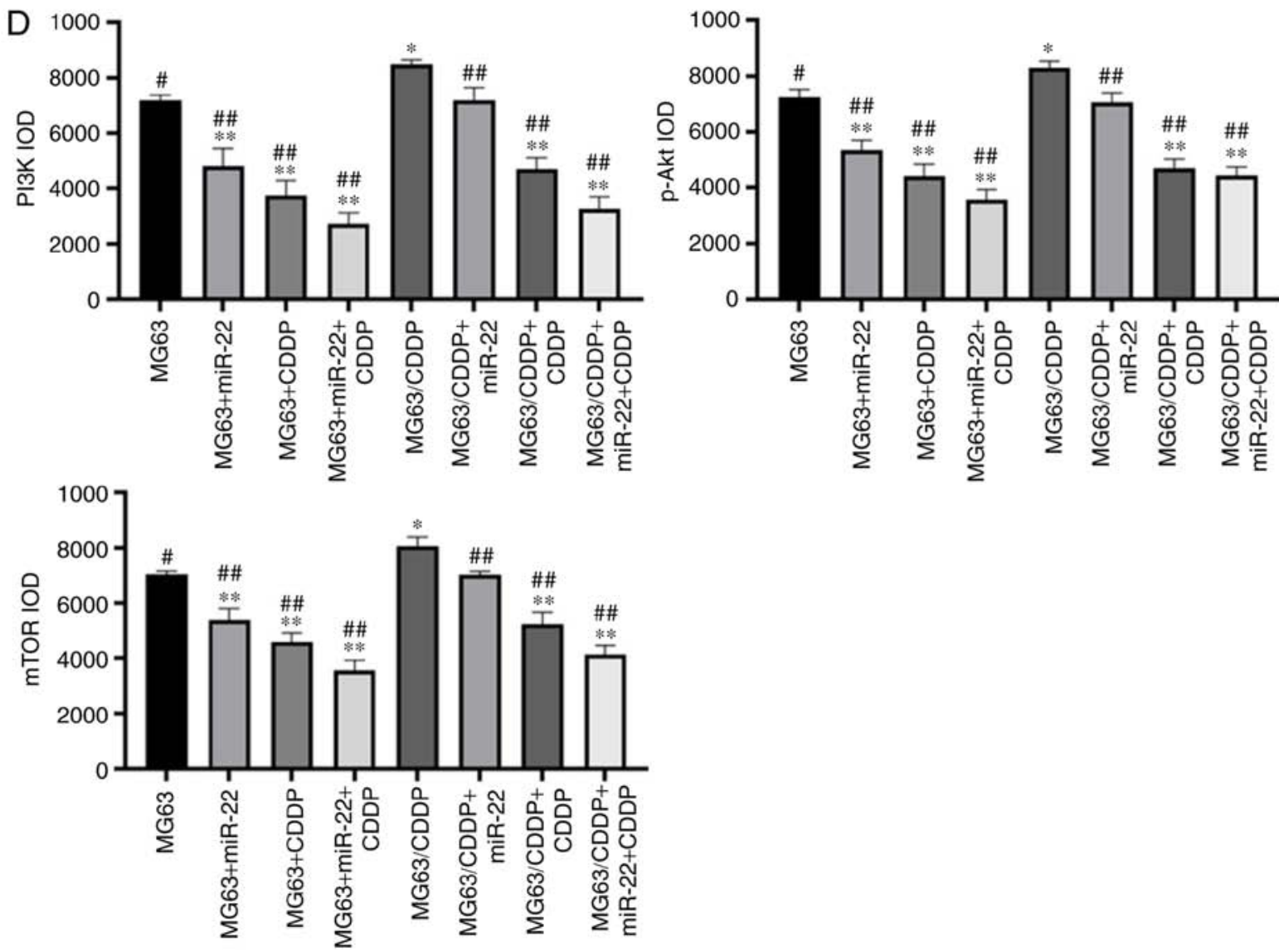

Figure 9. Continued. Immunohistochemistry results. Immunohistochemical results of (C) p-mTOR are shown. (D) The immunohistochemical IOD values of $\mathrm{PI} 3 \mathrm{~K}$, p-Akt, and p-mTOR after inoculation with MG63 and MG63/CDDP cells. ${ }^{*} \mathrm{P}<0.05$ and ${ }^{* *} \mathrm{P}<0.01$, compared with the control group of MG63; ${ }^{*} \mathrm{P}<0.05$ and ${ }^{\# \#} \mathrm{P}<0.01$, compared with the control group of MG63/CDDP. To determine the extent of phosphorylation of Akt, the value shown for $\mathrm{p}$-Akt is the ratio of the IODs of p-Akt and Akt; for p-mTOR, the extent of phosphorylation of mTOR is shown as the ratio of the IODs of p-mTOR and mTOR. PI3K, phosphoinositide 3-kinase; mTOR, mammalian target of rapamycin; p-, phosphorylated; CDDP, cisplatin; IOD, integrated optical density.

induce autophagy in endometrial cancer cells (44). In the present study, it was shown that the expression of PI3K, Akt, and mTOR was downregulated by miR-22 and CDDP, whereas these proteins were upregulated in the resistant cells. We surmised that drug resistance was obtained by activating autophagy via the PI3K/Akt/mTOR pathway. It could be hypothesized that 

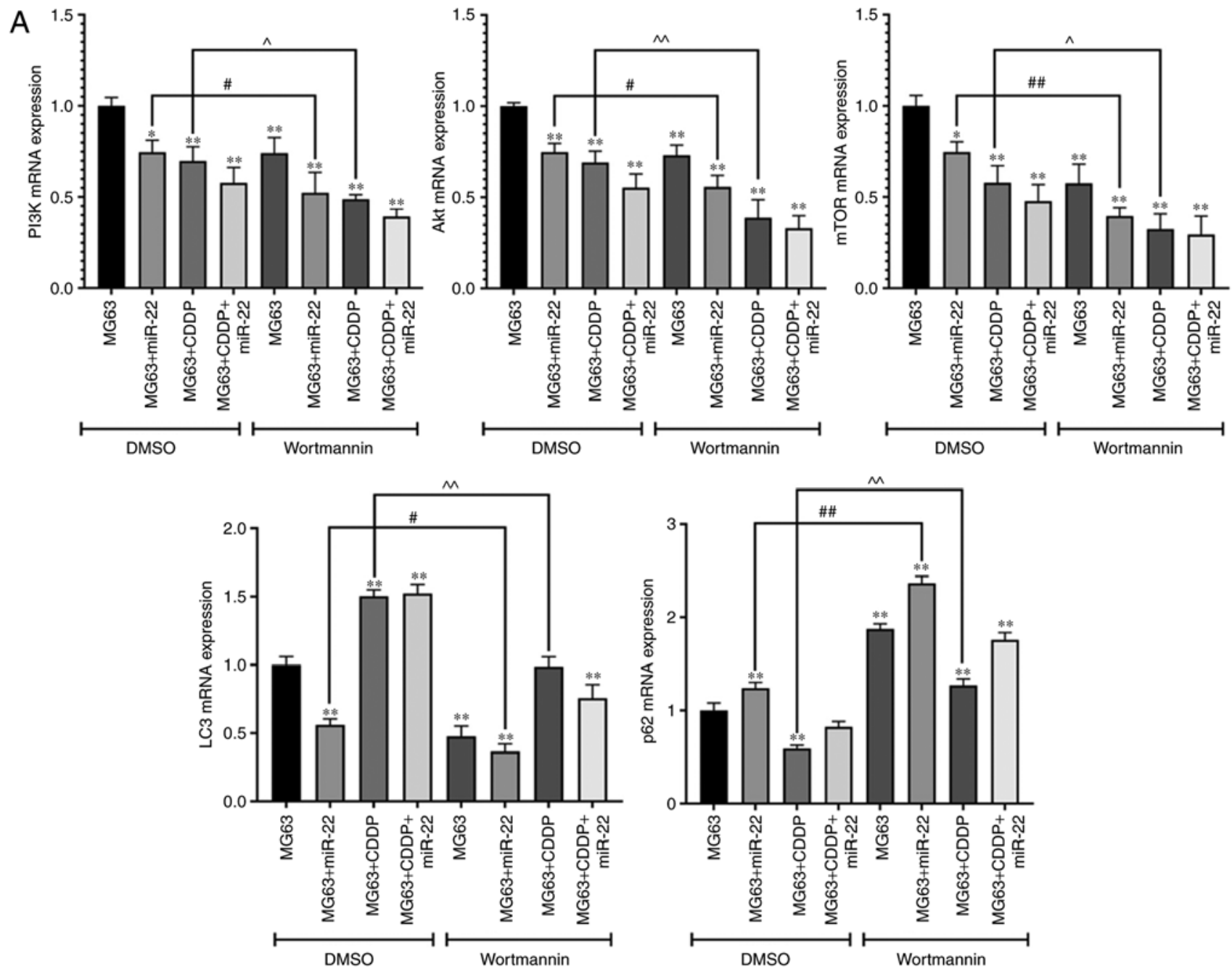

Figure 10. Effect of wortmannin on the mRNA and protein expression levels of PI3K, Akt and mTOR. (A) mRNA expression levels of PI3K, Akt and mTOR in the DMSO (control) group and the wortmannin-treated group are shown. ${ }^{*} \mathrm{P}<0.05$ and ${ }^{* *} \mathrm{P}<0.01$, compared with group MG63+DMSO. Further comparisons between two group are indicated with solid lines. The labels including \# and ${ }^{\wedge}$ on the top of solid lines means they are statistically significant: ${ }^{\#} \mathrm{P}<0.05$ and ${ }^{\# \#} \mathrm{P}<0.01$, the wortmannin group of MG63+CDDP compared with the DMSO group of MG63+CDDP; ${ }^{\wedge} \mathrm{P}<0.05$ and ${ }^{\wedge} \mathrm{P}<0.01$, the wortmannin group of MG63+miR-22 compared with the DMSO group of MG63+miR-22. To determine the extent of phosphorylation of Akt, the value shown for p-Akt is the ratio of the IODs of p-Akt and Akt; for p-mTOR, the extent of phosphorylation of mTOR is shown as the ratio of the IODs of p-mTOR and mTOR. PI3K, phosphoinositide 3-kinase; mTOR, mammalian target of rapamycin; p-, phosphorylated; CDDP, cisplatin; IOD, integrated optical density.

miR-22 is able to inhibit autophagy induced by CDDP and decrease drug resistance via the PI3K/Akt/mTOR pathway both in vivo and in vitro. The results of the present study coincided with the results of a previous study, which revealed which PI3K could be downregulated to inhibit autophagy, leading to suppression of MG63 cell proliferation activity and increasing the sensitivity to CDDP (45). A recent study argued that miR-22-3p enhances the chemosensitivity of gastrointestinal stromal tumor cell lines to CDDP via the phosphatase and tensin homolog deleted on chromosome 10 (PTEN)/PI3K/Akt pathway (26). Interestingly, in the present study, CDDP downregulated the PI3K/Akt/mTOR pathway, whereas it was able to induce autophagy. However, the upregulation of the $\mathrm{PI} 3 \mathrm{~K} / \mathrm{Akt} / \mathrm{mTOR}$ pathway occurred concomitantly with an increase in chemoresistance. This result suggested that CDDP may downregulate the PI3K/Akt/mTOR pathway to exert an antitumor effect, although excessive autophagy induced by CDDP may lead to upregulation of the PI3K/Akt/mTOR pathway to further increase the chemoresistance of CDDP.
In addition, downregulation of the PI3K/Akt/mTOR pathway was significant in terms of preventing chemoresistance. The present study provides new insight that miR-22 could play a role in enhancing the chemosensitivity of OS to CDDP by inhibiting the PI3K/Akt/mTOR pathway (26).

In conclusion, the present study demonstrated that miR-22 was able to both inhibit tumor cell proliferative activity and decrease CDDP resistance by inhibiting autophagy via the $\mathrm{PI} 3 \mathrm{~K} / \mathrm{Akt} / \mathrm{mTOR}$ pathway in vivo and in vitro. Although this is significant and novel information, the internal mechanism of the pathway, more target genes and associated pathways, and the precise details of the biological metabolism have yet to be elucidated, and require further study. Our study provides new insight into the anti-chemoresistance in OS, and may contribute to the development of novel therapeutic drugs.

\section{Acknowledgements}

No funding was received. 

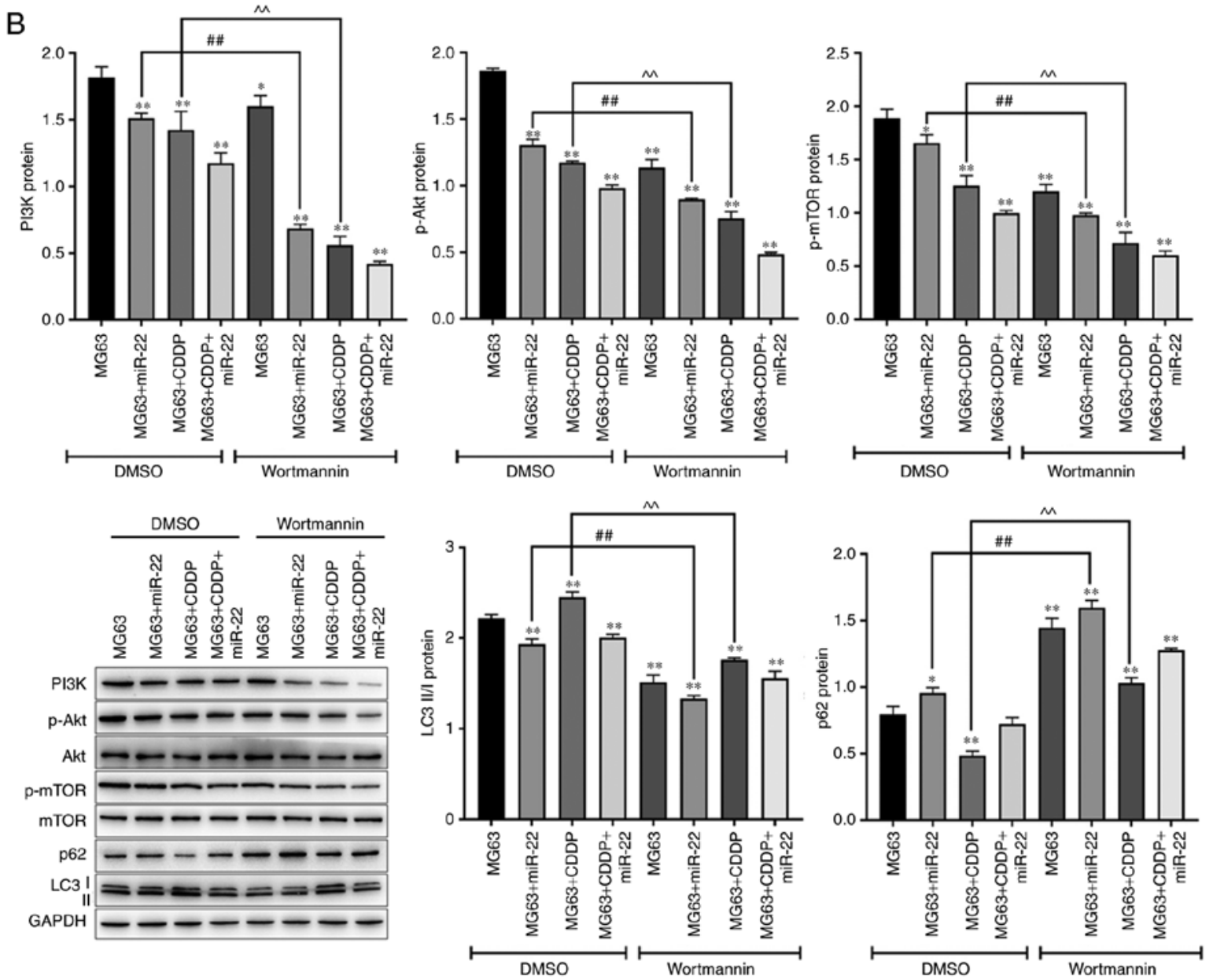

Figure 10. Continued. Effect of wortmannin on the mRNA and protein expression levels of PI3K, Akt and mTOR. (B) The protein expression levels of PI3K, p-Akt and p-mTOR are shown, as determined by western blot analysis. ${ }^{*} \mathrm{P}<0.05$ and ${ }^{* *} \mathrm{P}<0.01$, compared with group MG63+DMSO. Further comparisons between two group are indicated with solid lines. The labels including \# and ${ }^{\wedge}$ on the top of solid lines means they are statistically significant: ${ }^{\#} \mathrm{P}<0.05$ and ${ }^{\# \#} \mathrm{P}<0.01$, the wortmannin group of MG63+CDDP compared with the DMSO group of MG63+CDDP; ${ }^{\wedge} \mathrm{P}<0.05$ and ${ }^{\wedge} \mathrm{P}<0.01$, the wortmannin group of MG63+miR-22 compared with the DMSO group of MG63+miR-22. To determine the extent of phosphorylation of Akt, the value shown for p-Akt is the ratio of the IODs of p-Akt and Akt; for p-mTOR, the extent of phosphorylation of mTOR is shown as the ratio of the IODs of p-mTOR and mTOR. PI3K, phosphoinositide 3-kinase; mTOR, mammalian target of rapamycin; p-, phosphorylated; CDDP, cisplatin; IOD, integrated optical density.

\section{Funding}

The present study is supported by the National Natural Science Foundation of China (grant no. 81660440) and the Natural Science Foundation of Inner Mongolia (grant no. 2018MS08031).

\section{Availability of data and materials}

The analyzed datasets generated and/or analyzed during the current study are available from the corresponding author on reasonable request.

\section{Authors' contributions}

CYM, ZQZ, SBG, WF, CS, YXW and HQX participated in the design of the study and drafted the manuscript. RB, LS and WZ collected the data and performed the statistical analyses. CYM, ZQZ, SBG and WF were major contributors to the design of this study and revised the manuscript. All authors read and approved the manuscript and agree to be accountable for all aspects of the research in ensuring that the accuracy or integrity of any part of the work are appropriately investigated and resolved.

\section{Ethics approval and consent to participate}

All animal experiments were performed following the approval of the Inner Mongolia Medical University Animal Ethics Committee and according to the Guidelines for the Care and Use of Laboratory Animals.

\section{Patient consent for publication}

Not applicable.

\section{Competing interests}

The authors declare that they have no competing interests.

\section{References}

1. Ries LAG, Smith MA, Gurney JG, et al: Cancer incidence and survival among children and adolescents: United States SEER Program 1975-1995. 1999.

2. Mirabello L, Troisi RJ and Savage SA: Osteosarcoma incidence and survival rates from 1973 to 2004. Cancer 115: 1531-1543, 2010 . 
3. Bleyer A, O'Leary M, Barr R, et al: Cancer epidemiology in older adolescents and young adults 15 to 29 years of age, including SEER incidence and survival: 1975-2000. 2006.

4. Anninga JK, Gelderblom H, Fiocco M, Kroep JR, Taminiau AH, Hogendoorn PC and Egeler RM: Chemotherapeutic adjuvan treatment for osteosarcoma: Where do we stand? Eur J Cancer 47: 2431-2445, 2011

5. Kager L, Tamamyan G and Bielack S: Novel insights and therapeutic interventions for pediatric osteosarcoma. Future Oncol 13: 357-368, 2017

6. Farazi TA, Spitzer JI, Morozov P and Tuschl T: MiRNAs in human cancer. J Pathol 223: 102-115, 2015.

7. Bentwich I, Avniel A, Karov Y, Aharonov R, Gilad S, Barad O, Barzilai A, Einat P, Einav U, Meiri E, et al: Identification of hundreds of conserved and nonconserved human microRNAs. Nat Genet 37: 766-770, 2005

8. Croce CM: Causes and consequences of microRNA dysregulation in cancer. Nat Rev Genet 10: 704-714, 2009.

9. Gougelet A, Pissaloux D, Besse A, Perez J, Duc A, Dutour A, Blay JY and Alberti L: Micro-RNA profiles in osteosarcoma as a predictive tool for ifosfamide response. Int J Cancer 129 680-690, 2011

10. Torreggiani E, Roncuzzi L, Perut F, Zini N and Baldini N: Multimodal transfer of MDR by exosomes in human osteosarcoma. Int J Oncol 49: 189-196, 2016.

11. Fan MC and Jian W: Role of autophagy in cancer. Medical Recapitulate 7: 961, 2010.

12. Sheng C, Jiang YZ, Huang L, Zhou RJ, Yu KD, Liu Y and Shao ZM: The residual tumor autophagy marker LC3B serves as a prognostic marker in local advanced breast cancer after neoadjuvant chemotherapy. Clin Cancer Res 19: 6853-6862, 2013.

13. Yang ZJ, Chee CE, Huang S and Sinicrope FA: The role of autophagy in cancer: Therapeutic implications. Mol Cancer Ther 10: 1533-1541, 2011

14. Liu L, Yang M, Kang R, Wang Z, Zhao Y, Yu Y, Xie M, Yin X, Livesey KM, Lotze MT, et al: HMGB1-Induced autophagy promotes chemotherapy resistance in leukemia cells. Leukemia 25: 23-31, 2011.

15. Chang Z, Huo L, Li K, Wu Y and Hu Z: Blocked autophagy by miR-101 enhances osteosarcoma cell chemosensitivity in vitro. ScientificWorldJournal 2014: 794756, 2014

16. Chen $\mathrm{R}, \mathrm{Li} \mathrm{X}, \mathrm{He} \mathrm{B}$ and $\mathrm{Hu} \mathrm{W}$ : MicroRNA-410 regulates autophagy-related gene ATG16L1 expression and enhances chemosensitivity via autophagy inhibition in osteosarcoma. Mol Med Rep 15: 1326-1334, 2017.

17. Lagos-Quintana M, Rauhut R, Lendeckel W and Tuschl T: Identification of novel genes coding for small expressed RNAs. Science 294: 853-858, 2001.

18. Damavandi Z, Torkashvand S, Vasei M, Soltani BM, Tavallaei M and Mowla SJ: Aberrant expression of breast development-related microRNAs, miR-22, miR-132, and miR-212, in breast tumor tissues. J Breast Cancer 19: 148-155, 2016.

19. Li J, Zhang Y, Zhao J, Kong F and Chen Y: Overexpression of miR-22 reverses paclitaxel-induced chemoresistance through activation of PTEN signaling in p53-mutated colon cancer cells Mol Cell Biochem 357: 31-38, 2011.

20. Liu X, Zhang L, Tong Y, Yu M, Wang M, Dong D, Shao J, Zhang F, Niu R and Zhou Y: MicroRNA-22 inhibits proliferation, invasion and metastasis of breast cancer cells through targeting truncated neurokinin-1 receptor and ERalpha. Life Sci 217: 57-69, 2019.

21. Jiang W, Han X, Wang J, Wang L, Xu Z, Wei Q, Zhang W and Wang H: MiR-22 enhances the radiosensitivity of small-cell lung cancer by targeting the WRNIP1. J Cell Biochem 120: 17650-17661, 2019.

22. Zhou X, Natino D, Zhai X, Gao Z and He X: MicroRNA22 inhibits the proliferation and migration, and increases the cisplatin sensitivity, of osteosarcoma cells. Mol Med Rep 17: 7209-7217, 2018.

23. Guo S, Bai R, Liu W, Zhao A, Zhao Z, Wang Y, Wang Y, Zhao W and Wang W: MiR-22 inhibits osteosarcoma cell proliferation and migration by targeting HMGB1 and inhibiting HMGB1-mediated autophagy. Tumor Biol 35: 7025-7034, 2014.

24. Li X, Wang S, Chen Y, Liu G and Yang X: MiR-22 targets the 3 UTR of HMGB1 and inhibits the HMGB1-associated autophagy in osteosarcoma cells during chemotherapy. Tumor Biol 35 : 6021-6028, 2014.

25. Wang P, Zhao ZQ, Guo SB, Yang TY, Chang ZQ, Li DH, Zhao W, Wang YX, Sun C, Wang Y and Feng W: Roles of microRNA-22 in suppressing proliferation and promoting sensitivity of osteosarcoma cells via metadherin-mediated autophagy. Orthop Surg 11: 285-293, 2019.
26. Xu Y, Cheng M, Mi L, Qiu Y, Hao W and Li L: Mir-22-3p enhances the chemosensitivity of gastrointestinal stromal tumor cell lines to cisplatin through PTEN/PI3K/Akt Pathway. Iran J Allergy Asthma Immunol 17: 318-325, 2018.

27. Li Y, Geng P, Jiang W, Wang Y, Yao J, Lin X, Liu J, Huang L, Su B and Chen $\mathrm{H}$ : Enhancement of radiosensitivity by 5 -Aza-CdR through activation of $\mathrm{G} 2 / \mathrm{M}$ checkpoint response and apoptosis in osteosarcoma cells. Tumour Biol 35: 4831-4839, 2014.

28. Yang TM, Guo SF, Chen CR, Zhang XY and Li WG: Anti-Osteosarcoma effects and mechanisms of 4-O-amino-phenol-4'-demethylepipodophyllotoxin ether. J Pharm Pharmacol 60: 179-188, 2008.

29. Tang J, Shen L, Yang Q and Zhang C: Overexpression of metadherin mediates metastasis of osteosarcoma by regulating epithelial-mesenchymal transition. Cell Prolif 47: 427-434, 2014.

30. Ye H, Lin J, Yao X, Li Y, Lin X and Lu H: Overexpression of long non-coding RNA NNT-AS1 correlates with tumor progression and poor prognosis in osteosarcoma. Cell Physiol Biochem 45: 1904-1914, 2018

31. de la Calle C, Joubert PE, Law HK, Hasan M and Albert ML: Simultaneous assessment of autophagy and apoptosis using multispectral imaging cytometry. Autophagy 7: 1045-1051, 2011.

32. Sui X, Chen R, Wang Z, Huang Z, Kong N, Zhang M, Han W, Lou F, Yang J, Zhang Q, et al: Autophagy and chemotherapy resistance: A promising therapeutic target for cancer treatment. Cell Death Dis 4: e838, 2013

33. Mizushima N, Levine B, Cuervo AM and Klionsky DJ: Autophagy fights disease through cellular self-digestion. Nature 451: 1069-1075, 2008

34. Singh R, Kaushik S, Wang Y, Xiang Y, Novak I, Komatsu M, Tanaka K, Cuervo AM and Czaja MJ: Autophagy regulates lipid metabolism. Nature 458: 1131-1135, 2009

35. He C and Klionsky DJ: Regulation mechanisms and signaling pathways of autophagy. Annu Rev Genet 43: 67-93, 2009.

36. Chen L, Jiang K, Jiang H and Wei P: MiR-155 mediates drug resistance in osteosarcoma cells via inducing autophagy. Exp Ther Med 8: 527-532, 2014

37. Xu R, Liu S, Chen H and Lao L: MicroRNA-30a downregulation contributes to chemoresistance of osteosarcoma cells through activating beclin-1-mediated autophagy. Oncol Rep 35: 1757-1763, 2016.

38. Degenhardt K, Mathew R, Beaudoin B, Bray K, Anderson D, Chen G, Mukherjee C, Shi Y, Gélinas C, Fan Y, et al: Autophagy promotes tumor cell survival and restricts necrosis, inflammation, and tumorigenesis. Cancer Cell 10: 51-64, 2006.

39. Hussain A, Qazi AK, Mupparapu N, Guru SK, Kumar A, Sharma PR, Singh SK, Singh P, Dar MJ, Bharate SB, et al: Modulation of glycolysis and lipogenesis by novel PI3K selective molecule represses tumor angiogenesis and decreases colorectal cancer growth. Cancer Lett 374: 250-260, 2016.

40. Xiao X, Wang W, Li Y, Yang D, Li X, Shen C, Liu Y, Ke X, Guo S and Guo Z: HSP90AA1-Mediated autophagy promotes drug resistance in osteosarcoma. J Exp Clin Cancer Res 37: 201, 2018.

41. Leonardi GC, Falzone L, Salemi R, Zanghì A, Spandidos DA, Mccubrey JA, Candido S and Libra M: Cutaneous melanoma: From pathogenesis to therapy (Review). Int J Oncol 52: 1071-1080, 2018.

42. Zhang L and Han J: Branched-Chain amino acid transaminase (BCAT1) promotes the growth of breast cancer cells through improving mTOR-mediated mitochondrial biogenesis and function. Biochem Biophys Res Commun 486: 224-231, 2017.

43. Kumar S, Guru SK, Pathania AS, Manda S, Kumar A, Bharate SB, Vishwakarma RA, Malik F and Bhushan S: Fascaplysin induces caspase mediated crosstalk between apoptosis and autophagy through the inhibition of PI3K/AKT/mTOR signaling cascade in human leukemia HL-60 cells. J Cell Biochem 116: 985-997, 2015.

44. Lin Q, Wang Y, Chen D, Sheng X, Liu J and Xiong H: Cisplatin regulates cell autophagy in endometrial cancer cells via the PI3K/AKT/mTOR signalling pathway. Oncol Lett 13: 3567-3571, 2017.

45. Miao XD, Cao L, Zhang Q, Hu XY and Zhang Y: Effect of PI3K-mediated autophagy in human osteosarcoma MG63 cells on sensitivity to chemotherapy with cisplatin. Asian Pac J Trop Med 8: 731-738, 2015.

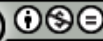

This work is licensed under a Creative Commons Attribution-NonCommercial-NoDerivatives 4.0 International (CC BY-NC-ND 4.0) License. 